Ligia R. Gomes, John N. Low*, Tanja van Mourik, Ligia S. da Silveira Pinto, Marcus V.N. de Souza and Jámes L. Wardell*

\title{
Crystal structures, Hirsfeld surface analysis and a computational study of four ethyl 2-0xo-2H-chromene-3-carboxylate derivatives: a survey of organyl 2-0xo-2H-chromene-3-carboxylate structures
}

https://doi.org/10.1515/zkri-2018-2117

Received July 8, 2018; accepted September 2, 2018

Abstract: Crystal structures, Hirshfeld surface analysis and a computational study have been carried out on 2-oxo-2H-chromene-3-carboxylates. Crystal structures are reported for ethyl R-2-oxo-2H-chromene-3-carboxylate derivatives, 2a: $\mathrm{R}=$ 6-Me, 2b: 7-Me, 2c: 7-Me, 2d: $\mathrm{R}=7-\mathrm{MeO}$. In contrast to 2-oxo-2H-chromene-3-carboxamides, $\mathbf{1}$, in which classical intramolecular $\mathrm{N}-\mathrm{H} \cdots \mathrm{O}$ hydrogen bonds stabilize planar structures and hinder rotation of the amido group out of the coumarin plane in $\mathbf{2}$, without an equivalent hydrogen bond, there is a greater rotational freedom of the carboxylate group. The interplanar angles between the coumarin core and its attached $-\mathrm{C}(\mathrm{O})-\mathrm{R}$ substituent in crystalline $\mathbf{2 a}, \mathbf{2 b}, \mathbf{2 c}$ and $\mathbf{2 d}$ are 10.41(6), 36.65(6), 10.4(2) and $5.64(6)^{\circ}$, respectively, with distances between the carbonyl oxygen atoms of 2.8255(16), 2.9278(16), 4.226(2) and 2.8328(14) A , respectively. A theoretical study of molecular conformations was carried out at the M06-2X density level with the 6-31+G(d) and aug-cc-pVTZ basis sets, in methanol solution modeled by PCM, indicated that the

*Corresponding authors: John N. Low, Department of Chemistry, University of Aberdeen, Meston Walk, Old Aberdeen, AB24 3UE, Scotland, UK, E-mail: jnlow111@gmail.com; and Jámes L. Wardell, Department of Chemistry, University of Aberdeen, Meston Walk, Old Aberdeen, AB24 3UE, Scotland, UK; and Instituto de Tecnologia em Fármacos e Farmanguinhos, Fundação Oswaldo Cruz, 21041-250 Rio de Janeiro, RJ, Brazil, E-mail: j.wardell@abdn.ac.uk

Ligia R. Gomes: FP-ENAS-Faculdade de Ciências de Saúde, Escola Superior de Saúde da UFP, Universidade Fernando Pessoa, Rua Carlos da Maia, 296, P-4200-150 Porto, Portugal; and REQUIMTE, Departamento de Química e Bioquímica, Faculdade de Ciências da Universidade do Porto, Rua do Campo Alegre, 687, P-4169-007, Porto, Portugal

Tanja van Mourik: School of Chemistry, University of St. Andrews, North Haugh, St. Andrews, Fife KY16 9ST, Scotland, UK Ligia S. da Silveira Pinto: Universidade Federal do Rio de Janeiro, Instituto de Química, Departamento de Química Orgânica, CP 68563, 21945-970, Rio de Janeiro, Brazil; and Instituto de Tecnologia em Fármacos e Farmanguinhos, Fundação Oswaldo Cruz, 21041-250 Rio de Janeiro, RJ, Brazil

Marcus V.N. de Souza: Instituto de Tecnologia em Fármacos e Farmanguinhos, Fundação Oswaldo Cruz, 21041-250 Rio de Janeiro, RJ, Brazil most stable conformations had the carbonyl group of the ester in the plane of the coumarin core: the s-cis arrangement of the ester carbonyl and the 2-oxo moieties being the slightly more stable than the $s$-trans form by less than $0.5 \mathrm{kcal} / \mathrm{mol}$. The experimental conformations of $\mathbf{2 a}$ and $\mathbf{2 d}$ match well the low energy s-cis arrangement, and $\mathbf{2 c}$ matches the slightly lesser stable s-trans arrangement found in the theoretical study. A survey of the molecular conformations of more than $502 \mathrm{H}$-chromene-3-carboxylates derivatives in the CCDC data base indicated two distinct groupings of conformations, s-cis and s-trans, each with interplanar angles $<30^{\circ}$.

Keywords: 2-oxo-2H-chromene-3-carboxylate derivatives; crystal structures; density functional theory; Hirshfeld surface analysis; molecular conformation.

\section{Introduction}

$2 \mathrm{H}$-Chromene-2-ones, or coumarins, are a group of natural product found in many plant species belonging to the benzopyrone family. Derivatives, both natural and man-made, have been found to have a wide range of pharmacological activities [1-3], including as anti-HIV [4, 5], antibacterial [6, 7], antifungal [8], anti-inflammatoryl [9], anti-TB [10, 11], antileishmanial [12], antimalarial [13], antitumor [14-16], and antidepressant activities [17], and act as anticoagulants [18], $\alpha$-glucosidase inhibitors [19], topoisomerase II inhibitors [20], cholinesterase inhibitors [21], Alzheimer's diseaseinhibitors [22], and antioxidants [23, 24]. Coumarins also have applications in cosmetics and can be used as optical brightening agents, laser dyes, and fluorescence markers $[25,26]$ and as liquid crystals [27].

The synthesis of the $2 \mathrm{H}$-chromene-2-ones nucleus was first described in 1868 [28]. Since then, in keeping with their utilities, various synthetic procedures have been devised $[29,30]$. The interest in establishing new synthetic routes continues today [31-33]. Among the recent developments has been the use of ultrasonics in the reactions between active methylene compounds and 2-hydroxybenzaldehydes or resorcinol [34]. 
As part of our ongoing structural studies of compounds having biological activities [35-38], some of us have reported the structures of 2-oxo- $2 \mathrm{H}$-chromene-3-carboxamides, 1, see Figure $1[39,40]$. These studies, and a survey of related compounds in the CCDC data base, indicated the near planarity of such molecules arising from the very strong classical intramolecular $\mathrm{N}-\mathrm{H} \cdots \mathrm{O}$ hydrogen bond, involving the amido group and the chromene carbonyl oxygen atom, which essentially fixes the overall conformation to be near planar, see Figure 1. Alkyl 2-oxo$2 \mathrm{H}$-chromene-3-carboxylates, 2 , see Figure 1 , do not possess the ability to form a strong intramolecular hydrogen bond from the carboxylate and oxo group. Without a strong stabilizing hydrogen bond, compounds $\mathbf{2}$ will have the freedom to rotate about the coumarin-carboxylate bond and thus have potential for a range of differing conformations.

With ready access to alkyl 2-oxo-2H-chromene3-carboxylates, prepared using ultrasonics [34], we initiated a crystal structural and Hirshfeld surface study of such carboxylates. Four compounds were chosen, for study, namely 3-ethoxycarbonyl-6-methylcoumarin, 2a, 3-ethoxycarbonyl-7-methylcoumarin, 3-ethoxycarbonyl-8-methylcoumarin, 2c and 3-ethoxycarbonyl-7-methoxycoumarin, 2d, see Figure 1. Each of the chosen compounds has relatively small substituents in order to avoid the influence of serious steric effects on the structures. The structures were solved from data collected at $100 \mathrm{~K}$. The crystal structure of $\mathbf{2 d}$ had been previously determined from data collected at $296 \mathrm{~K}$ (Ref. [41]: CCDC. KIWCIE: 928907): the same phase was obtained at both temperatures.

The molecular conformation is the basic building block for developing the crystal structure and thus is an important feature to investigate. However, due to the possibility of bond rotation in solution, the solid state conformation may be greatly changed on dissolution. To see what changes may occur in a model solvent, a computational study of the molecular conformations of the compounds was carried out at the M06-2X density level with the $6-31+\mathrm{G}(\mathrm{d})$ and aug-cc-pTVZ basis sets, in methanol solution modelled by the Polarizable Continuum Model.

Comparisons of the structural features found in this study were made with those of organyl $2 \mathrm{H}$-chromene3-carboxylate compounds present in the CCDC data on Jun 22nd, 2017.

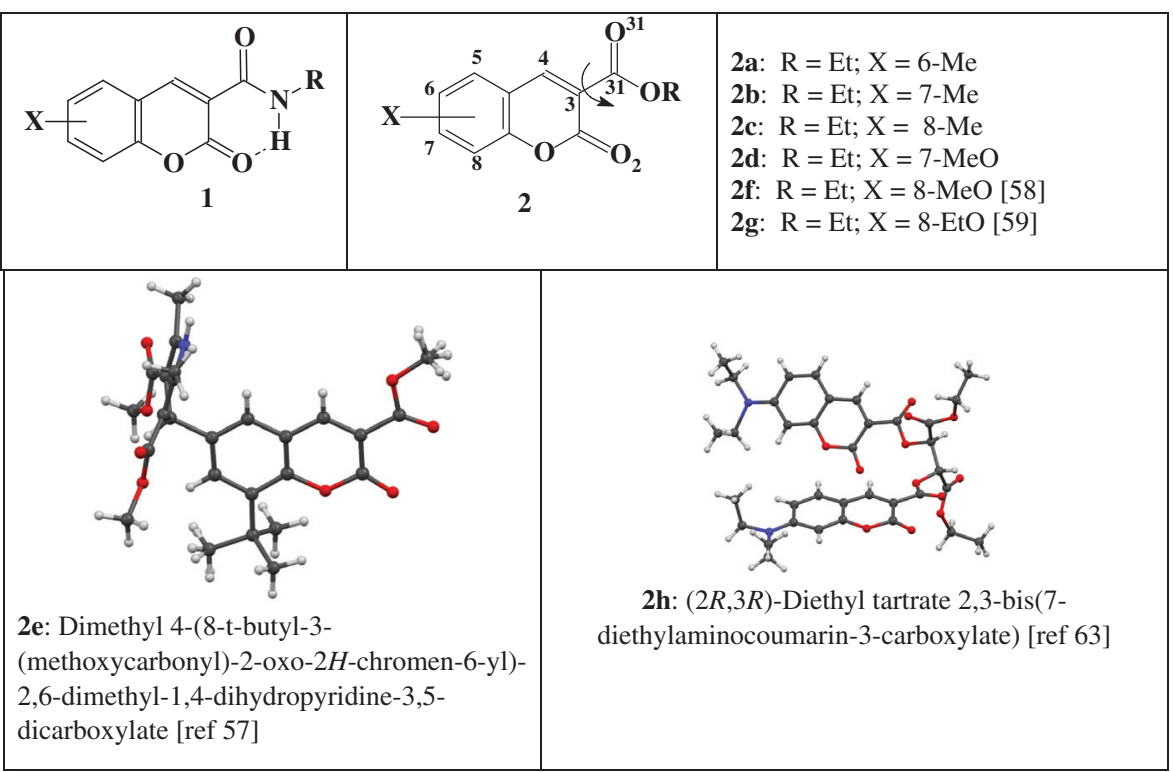

(a)

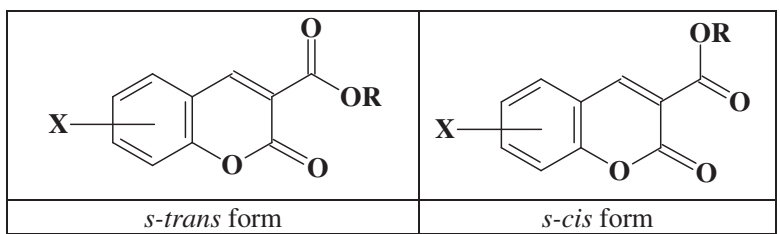

(b)

Fig. 1: (a) Compounds dealt with in this study, (b) cis and trans forms of 2. 


\section{Experimental}

\section{General synthesis}

The compounds were produced as previously reported, see Scheme 1 [34]. The samples used in the crystal structure determinations were grown from methanol solutions. Physical properties were in agreement with reported values [34].

\section{Experimental crystallography}

Details of the data collection and refinement are given in Table 1 [42-47].

\section{The Hirshfeld surface analysis}

The Hirshfeld surfaces and two-dimensional fingerprint (FP) plots [48] were generated using Crystal Explorer 3.1 [49]. The Hirshfeld surfaces were mapped over $d_{\text {norm }}$ (all scaled between -0.250 and 1.200). The Hirshfeld surfaces and FP plots for the four compounds are discussed at appropriate points in the Results and Discussion section.

\section{Computational methodology}

Starting structures for geometry optimizations were created from the $\mathrm{X}$-ray crystal structures of the different coumarins, with further geometries formed by rotating around the flexible bonds. Dihedral angles of 0 and $180^{\circ}$ were used for the rotation of the ${ }_{\text {(coumarin) }} \mathrm{C}-\mathrm{O}_{(\mathrm{OEt})}$ bond in all four molecules and for the $\mathrm{O}-\mathrm{CH}_{3}$ bond in $\mathbf{2 d}$, and values of 0,90 , 180 and $270^{\circ}$ for the last two bonds in the $\mathrm{O}=\mathrm{C}-\mathrm{O}-\mathrm{CH}_{2}-\mathrm{CH}_{3}$ moiety. The structures were optimized using the M06-2X density functional [50] and the $6-31+\mathrm{G}(\mathrm{d})$ basis set, in methanol solution modelled by the Polarizable Continuum Model [51] using the integral equation formalism variant (IEFPCM). The optimized structures were sorted into different groups $(\mathrm{A}-\mathrm{G})$ and selected conformers were re-optimized at the M06-2X/aug-cc-pVTZ level [52, 53]. All calculations were carried out with Gaussian 09 [54] and employed Gaussian's “ultrafine” integration

Tab. 1: Crystallographic details.

\begin{tabular}{|c|c|c|c|c|}
\hline & $2 a$ & $2 b$ & $2 c$ & $2 d$ \\
\hline \multicolumn{5}{|l|}{ Crystal data } \\
\hline $\begin{array}{l}\text { Chemical formula } \\
M_{r}\end{array}$ & $\begin{array}{l}\mathrm{C}_{13} \mathrm{H}_{12} \mathrm{O}_{4} \\
232.23\end{array}$ & $\begin{array}{l}\mathrm{C}_{13} \mathrm{H}_{12} \mathrm{O}_{4} \\
232.23\end{array}$ & $\begin{array}{l}\mathrm{C}_{13} \mathrm{H}_{12} \mathrm{O}_{5} \\
248.23\end{array}$ & $\begin{array}{l}\mathrm{C}_{13} \mathrm{H}_{12} \mathrm{O}_{4} \\
232.23\end{array}$ \\
\hline Crystal system, space group & Monoclinic, $C 2 / c$ & Monoclinic, $P 2_{1} / c$ & Monoclinic, $C 2 / c$ & Monoclinic, $C 2 / c$ \\
\hline Temperature (K) & 100 & 100 & 100 & 100 \\
\hline$a, b, c(\AA)$ & $\begin{array}{l}23.8307(5), \\
7.1205(2), 13.4435(8)\end{array}$ & $\begin{array}{l}13.1258(5), \\
6.5711(2), 12.7688(4)\end{array}$ & $\begin{array}{l}25.6082(11) \\
6.8565(3), 13.4709(8)\end{array}$ & $\begin{array}{l}35.010(3), 4.6438(3), \\
13.5997(8)\end{array}$ \\
\hline$\beta\left(^{\circ}\right)$ & $108.450(4)$ & $96.374(3)$ & $104.060(5)$ & $94.795(7)$ \\
\hline$V\left(\AA^{3}\right)$ & $2163.93(16)$ & $1094.51(6)$ & $2294.4(2)$ & $2203.3(3)$ \\
\hline$Z$ & 8 & 4 & 8 & 8 \\
\hline Radiation type & Mo $K \alpha$ & Mo $K \alpha$ & Mo $K \alpha$ & Mo $K \alpha$ \\
\hline$\mu\left(\mathrm{mm}^{-1}\right)$ & 0.11 & 0.11 & 0.11 & 0.10 \\
\hline Crystal size $(\mathrm{mm})$ & $0.12 \times 0.06 \times 0.04$ & $0.14 \times 0.06 \times 0.05$ & $0.14 \times 0.12 \times 0.07$ & $0.08 \times 0.05 \times 0.01$ \\
\hline \multicolumn{5}{|c|}{$\begin{array}{l}\text { Data collection } \\
\text { - Diffractometer: Rigaku FRE+ equipped with HF Varimax confocal mirrors and an AFC12 goniometer and HG Saturn 724+ detector } \\
\text { diffractometer } \\
\text { - Absorption correction: Multi-scan CrysAlis PRO 1.171.39.9g (Rigaku Oxford Diffraction, 2015) Empirical absorption correction using } \\
\text { spherical harmonics, implemented in SCALE3 ABSPACK scaling algorithm }\end{array}$} \\
\hline$T_{\min }, T_{\max }$ & $0.804,1.000$ & $0.658,1.000$ & $0.910,1.000$ & $0.731,1.000$ \\
\hline $\begin{array}{l}\text { No. of measured, independent } \\
\text { and observed }[I>2 \sigma(I)] \text { reflections }\end{array}$ & $9681,2481,2023$ & $9755,2493,1938$ & $9872,2627,2242$ & $15178,2511,2272$ \\
\hline$R_{\text {int }}$ & 0.029 & 0.036 & 0.024 & 0.047 \\
\hline$(\sin \theta / \lambda)_{\max }\left(\AA^{-1}\right)$ & 0.649 & 0.649 & 0.649 & 0.649 \\
\hline \multicolumn{5}{|l|}{ Refinement } \\
\hline$R\left[F^{2}>2 \sigma\left(F^{2}\right)\right], w R\left(F^{2}\right), S$ & $0.043,0.110,1.05$ & $0.045,0.106,1.03$ & $0.039,0.109,1.07$ & $0.076,0.195,1.19$ \\
\hline No. of reflections & 2481 & 2493 & 2627 & 2511 \\
\hline No. of parameters & 156 & 156 & 165 & 156 \\
\hline $\mathrm{H}$-atom treatment & $\begin{array}{l}\mathrm{H} \text {-atom parameters } \\
\text { constrained }\end{array}$ & $\begin{array}{l}\mathrm{H} \text {-atom parameters } \\
\text { constrained }\end{array}$ & $\begin{array}{l}\mathrm{H} \text {-atom parameters } \\
\text { constrained }\end{array}$ & $\begin{array}{l}\mathrm{H} \text {-atom parameters } \\
\text { constrained }\end{array}$ \\
\hline$\Delta \rho_{\max }, \Delta \rho_{\min }\left(\mathrm{e} \AA^{-3}\right)$ & $0.34,-0.27$ & $0.34,-0.26$ & $0.43,-0.19$ & $0.68,-0.30$ \\
\hline CCDC no. & 1573020 & 1573018 & 1573019 & 1573021 \\
\hline
\end{tabular}

Computer programs: CrysAlis PRO 1.171.39.9g [42]; SHELXT [43]; ShelXle [44] SHELXL2014/17, SHELXL7 [45]; Mercury [46]; PLATON [47]. 
grid. Relaxed energy profiles were generated for rotation of the $\mathrm{C}(\mathrm{O})$ $\mathrm{OCH}_{2} \mathrm{CH}_{3}$ chain for forms Aa and $\mathrm{Ca}$ of coumarin $\mathbf{2 d}$ by optimizing the molecule at fixed torsion angle values with step sizes of $10^{\circ}$.

\section{Results and discussion}

The colourless compounds, $\mathbf{2 a - 2 d}$, crystallize in monoclinic phases: compounds $\mathbf{2 a}, \mathbf{2} \mathbf{b}$ and $\mathbf{2 d}$ in the $C 2 / c$ with $Z=8$ and compound $\mathbf{2 c}$ in the $P 2_{1} / c$ with $Z=4$. The asymmetric unit in each case was a single molecule. The atom arrangements and numbering schemes are illustrated in Figure 2.

\section{Molecular conformations of $2 a-2 d$}

The coumarin cores are very near planar in each of the four compounds: in compound 2a, ring atom outliers from the best planes are C4A [at 0.023(1)] and C3 [at -0.015(1)], with the exocyclic carbonyl atom, 02, -0.039(1) Å out of the best plane; in compound $\mathbf{2} \mathbf{b}$, ring atom outliers from the best

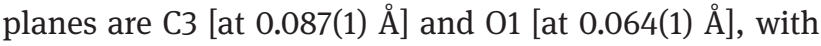
the exocyclic carbonyl atom, $02-0.061(1) \AA$ A out of the best plane; in compound 2c, ring atom outliers from the best planes are C3 [at 0.014(2) $\AA$ ] and C2 [at -0.011(2) $\AA$ ], with the exocyclic carbonyl atom, 02-0.034(1) Å out of the best plane; and in compound $\mathbf{2 d}$, ring atom outliers from the best planes are C2 [at 0.010(1) $\AA$ ] and 01 [at $-0.020(1) \AA]$, with the exocyclic carbonyl atom, 02 0.022(1) Å out of the best plane.

Selected bond lengths and angles are displayed in Table 2. As shown in Table 2, the $\mathrm{C}-\mathrm{C}$ bond lengths in the pyran-2-one ring vary between 1.354(2) and 1.473(2) A. Thus despite each carbon atom in the ring being formally $\mathrm{sp}^{2}$ hydridiZed with the sixth atom in the ring an oxygen atom, there is not complete $\pi$ electron delocalization within the pyran-2-one ring.

As shown by the torsion angles and the $02-031$ distances, listed in Table 2, there are differences in the molecular conformations, for example, the values of the $\mathrm{C} 2-$ C3-C31-031 torsion are 170.28(12), -146.89(13) and -8.2(3) are $174.979(10)^{\circ}$, and the $\mathrm{d}(02-031)$ distances are 2.8255(16), 2.9278(16), 4.226(2) and 2.8328(14) $\AA$, respectively for 2a-2d. The molecular conformation of compounds $\mathbf{2 a}$ and $\mathbf{2 d}$, as judged by the shorter $\mathrm{d}(\mathrm{O} 2-\mathrm{O} 31)$ distances, will be termed a $s$-cis conformation, and that of $2 \mathrm{c}$ will be termed, due to the longer $\mathrm{d}(\mathrm{O} 2-\mathrm{O} 31)$ distance, a s-trans conformation, see also

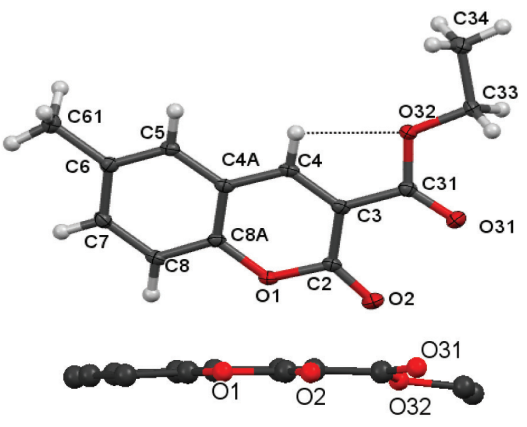

2a

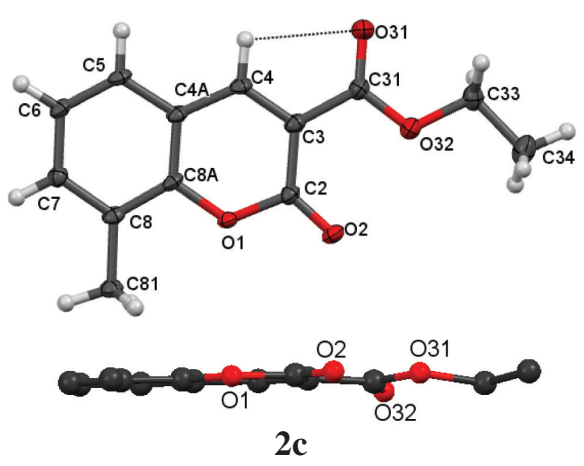

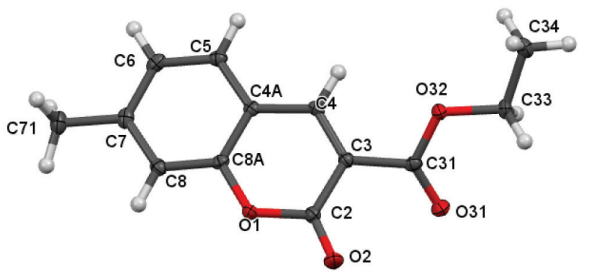

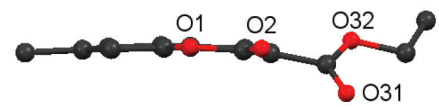

2b

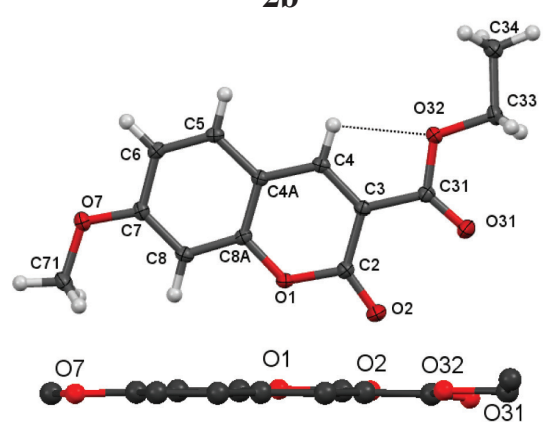

2d

Fig. 2: Atom arrangements and side-on views of the molecular conformations of $\mathbf{2 a - 2 d}$. Probability ellipsoids have been drawn at the $50 \%$ level. Intramolecular hydrogen bonds have been drawn as thin dashed lines. 
Tab. 2: Selected torsion angles $\left(^{\circ}\right)$ and distances, $\AA$, in compounds, $\mathbf{2 a - 2 d}$.

\begin{tabular}{|c|c|c|c|c|}
\hline Angle/distance & $2 a$ & 2b & 2c & $2 d$ \\
\hline $\mathrm{C} 2-02$ & $1.2040(17)$ & $1.2002(18)$ & $1.204(3)$ & $1.2056(15)$ \\
\hline $\mathrm{C} 2-\mathrm{C} 3$ & $1.473(2)$ & $1.4697(19)$ & $1.462(3)$ & $1.4671(16)$ \\
\hline $\mathrm{C} 3-\mathrm{C} 4$ & $1.355(2)$ & $1.354(2)$ & $1.356(3)$ & $1.3615(15)$ \\
\hline $\mathrm{C} 4-\mathrm{C} 4 \mathrm{~A}$ & $1.4342(19)$ & $1.434(2)$ & $1.430(3)$ & $1.4313(15)$ \\
\hline $\mathrm{C} 4 \mathrm{~A}-\mathrm{C} 8 \mathrm{~A}$ & $1.398(2)$ & 1.3965(19) & $1.394(30$ & $1.3954(16)$ \\
\hline $\mathrm{C} 8 \mathrm{~A}-01$ & $1.3777(17)$ & $1.3908(19)$ & $1.372(3)$ & $1.3761(14)$ \\
\hline $01-C 2$ & $1.3865(16)$ & $1.3908(17)$ & $1.384(3)$ & $1.4019(15)$ \\
\hline C3-C31 & $1.4905(19)$ & $1.490(2)$ & $1.497(3)$ & $1.4951(15)$ \\
\hline C31-031 & $1.2102(19)$ & $1.2050(18)$ & $1.213(3)$ & $1.2069(15)$ \\
\hline C31-032 & $1.3436(17)$ & $1.3389(17)$ & $1.333(3)$ & $1.3386(14)$ \\
\hline $032-C 33$ & $1.4510(16)$ & $1.4615(19)$ & $1.457(3)$ & $1.4580(14)$ \\
\hline C33-C34 & $1.506(2)$ & $1.505(2)$ & $1.506(4)$ & $1.516(17)$ \\
\hline $031-02$ & $2.8255(16)$ & $2.9278(16)$ & $4.226(2)$ & $2.8328(14)$ \\
\hline $031-C 31-C 3-C 2$ & $-9.2(2)$ & $36.0(2)$ & $172.0(2)$ & $-4.89(18)$ \\
\hline $\mathrm{O} 32-\mathrm{C} 31-\mathrm{C} 3-\mathrm{C} 2$ & $170.28(12)$ & $-146.89(13)$ & $-8.2(3)$ & $174.97(10)$ \\
\hline C $31-032-C 33-C 34$ & $-178.26(11)$ & $-178.07(12)$ & $-179.7(2)$ & $173.73(10)$ \\
\hline $\mathrm{C} 4-\mathrm{C} 3-\mathrm{C} 31-032$ & $-6.54(18)$ & $36.89(19)$ & $173.8(2)$ & $-5.93(15)$ \\
\hline $\mathrm{C} 4-\mathrm{C} 3-\mathrm{C} 31-031$ & $174.00(14)$ & $-140.20(15)$ & $-6.1(3)$ & $174.22(12)$ \\
\hline $\begin{array}{l}\text { Interplanar angles between the } \\
\text { coumarin core and the } \operatorname{EtO}(0) \text { side chain }\end{array}$ & $10.41(6)$ & $36.65(6)$ & $10.4(2)$ & $5.64(6)$ \\
\hline
\end{tabular}

Figure 2. The molecular conformation of $\mathbf{2 b}$ is somewhat in between the s-cis and s-trans conformations, from both the torsional angles and the $\mathrm{d}(\mathrm{O} 2-\mathrm{O} 31)$ distance, but is clearly much closer to the s-cis form.

\section{Theoretical study of the molecular conformations in compounds $\mathbf{2 a - 2 d}$}

To further investigate the s-cis and s-trans molecular conformations, calculations were carried out at the M06$2 \mathrm{X} / 6-31+\mathrm{G}(\mathrm{d})^{\star}$ and M06-2X/aug-cc-pVTZ levels in implicit methanol solution [50-52]. Methanol was chosen as it was the solvent used for the recrystallizations. All possible conformations of the side chains have been considered and have been grouped in different categories, based on the extent of the rotations involving the $\mathrm{C}(\mathrm{O}) \mathrm{OEt}$ group, and additionally in $\mathbf{2 d}$ that of the OMe group. Figures and energies for the most stable conformations are shown in Figure 3, with the more energetic conformations are also shown in the Supplementary Figure 1. For compounds 2a-2d, the A and C forms (s-cis forms) and B and D forms (s-trans-forms), respectively, have the ${ }_{\text {(coumarin) }} \mathrm{C}(=\mathrm{O})-\mathrm{C}_{\text {(OEt) }}$ fragment coplanar with its attached $2 \mathrm{H}$-chromen-2-one unit, see Figure 3. There are only small energy differences between the A-D forms, but, of interest, 2a has the A form, whilst compound $\mathbf{2 b}$ has the B form. It is apparent that crystal packing effects result in compound $\mathbf{2 c}$ being distorted from an ideal cis form. With consideration also of additional rotational changes involving the methoxy group in $\mathbf{2 d}$ there are more conformations to consider. Variation of the methyl group about the coumarin unit does lead to stability differences (compare $\mathrm{Xa}$ and $\mathrm{Xb}$ structures: $\mathrm{X}=\mathrm{A}, \mathrm{B}$, etc). However, the most stable arrangement for $\mathbf{2 d}$ is calculated to bethe s-cis form, Aa, though the s-trans form, $\mathrm{Ba}$, is nearly iso-energetic. Of interest, the solid state experimental form of $2 \mathrm{~d}$ matches exactly that of the theoretical solution-phase form.

Figure 4 shows the variation in conformer stability on rotating the ${ }_{\text {(coumarin) }} \mathrm{C}-\mathrm{O}_{(\text {(OEt) }}$ unit out of the plane of the $2 \mathrm{~d}$ coumarin core for the Aa and Ca forms. The profiles pass through the Ba and Da forms, respectively (Aa and Ca are located near $0^{\circ} \mathrm{Ba}$ and Da near $180^{\circ}$, in the profiles). The differences between the $\mathrm{Aa}$ and $\mathrm{Ca}$ pair and between the $\mathrm{Ba}$ and Da pair involve rotations about the $\mathrm{O}-\mathrm{CH}_{2}$ bond of the ethyl group. As shown in Figure 4, rotations in the case of $\mathrm{Aa}$ and $\mathrm{Ca}$ from $\mathrm{O}^{\circ}$, and in the case for $\mathrm{Ba}$ and $\mathrm{Da}$, from $180^{\circ}$, result in higher energies. Overall the most stable arrangements are $\mathrm{Aa}$ and $\mathrm{Ba}$, in which the ethyl group is fully extended.

\section{Intermolecular interactions in $\mathbf{2 a - 2 d}$}

The intermolecular interactions in $\mathbf{2 a - 2} \mathbf{d}$, as established by both the PLATON and Hirshfeld surface analyses, are listed in Table 3. Present in all four compounds are $\mathrm{C}-\mathrm{H} \cdots \mathrm{O}$ and $\pi \cdots \pi$ interactions, while compound 2a also exhibits a $\mathrm{C}=0 \cdots \pi$ interaction. Table 4 lists the contributions of various contacts, selected by the partial 
(a) Compound 2a

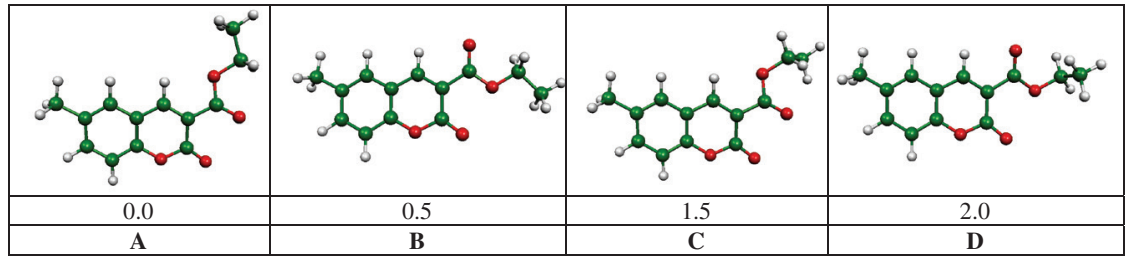

(b) Compound 2b

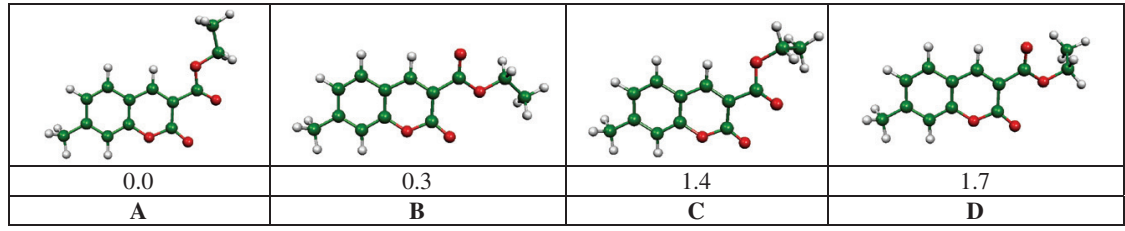

(c) Compound 2c

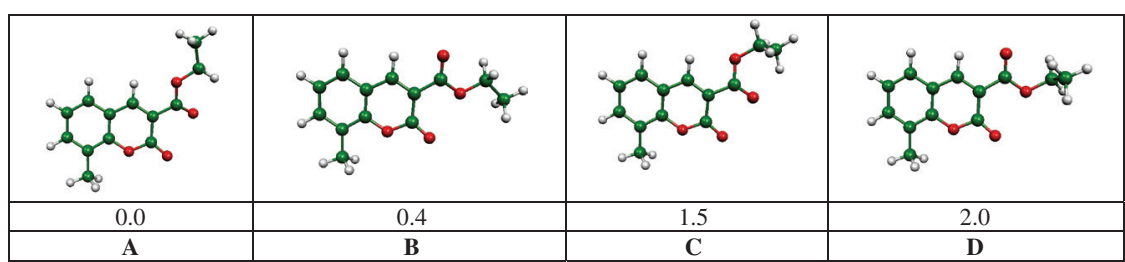

(c) Compound 2d

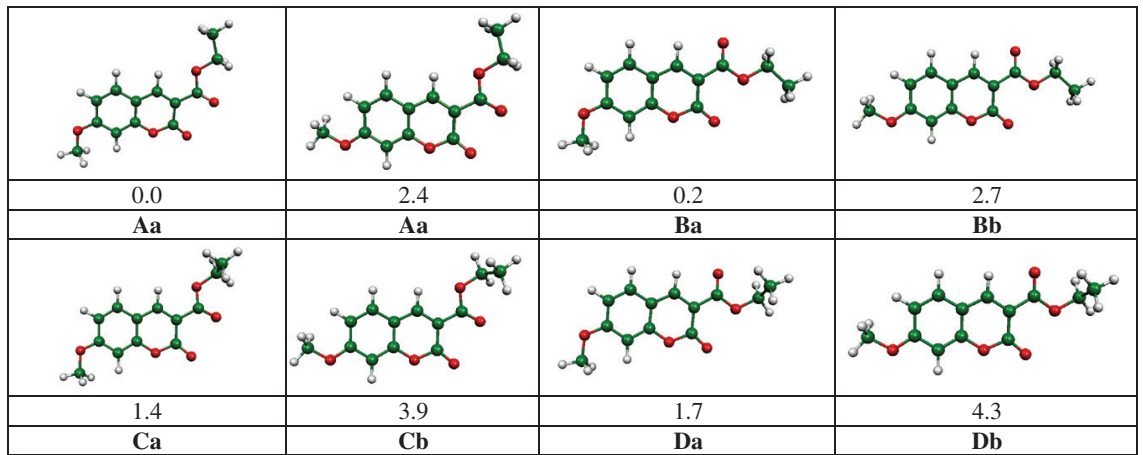

Fig. 3: Relative energies (kJ/mol) of the conformations, A-D, calculated at the M06-2X/aug-cc-pVTZ for compounds 2.

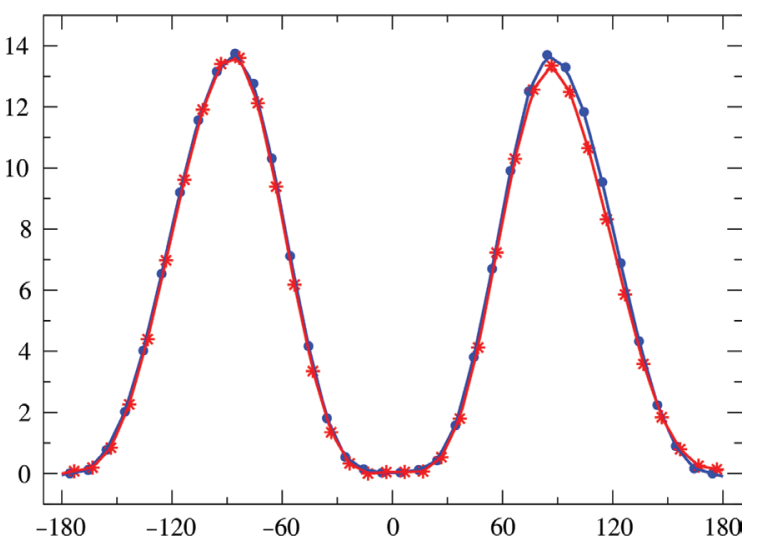

Fig. 4: Variation of energy, $\mathrm{kJ} / \mathrm{mol}^{-1}$, of conformations on angle of rotation of the ester side chain about the coumarin core: minima for $A$ and $C$ scans occur at $0^{\circ}$ and for $B$ and $D$ at $180^{\circ}$. analysis of the FP plots. Some conclusions from Table 4 for the three isomers, $\mathbf{2} \mathbf{a}-\mathbf{2} \mathbf{c}$ are (i) $\mathbf{2 b}$ has the highest combined percentages of $\mathrm{O} \cdots \mathrm{H} / \mathrm{H} \cdots \mathrm{O}$ and $\mathrm{H} \cdots \mathrm{C} / \mathrm{C} \cdots \mathrm{H}$ interactions, but the lowest percentage of $\mathrm{H} \cdots \mathrm{H}$ contacts and (ii) $\mathbf{2 c}$ has the highest percentage of $\mathrm{C} \cdots \mathrm{C}$ contacts of the three isomers. Comparison of the two compounds, 2c and $\mathbf{2 d}$, both with substituents in the 7-position, indicates that the most significant differences are with the $\mathrm{H} \cdots \mathrm{C} / \mathrm{C} \cdots \mathrm{H}$ and $\mathrm{C} \cdots \mathrm{C}$ contacts.

Although each compound has its own set of intermolecular interactions, some common, albeit superficial, features are apparent. These are (i) chain formations utilizing at least the $\mathrm{O} 2$ oxygen atom and (ii) sub-structures involving $\pi \cdots \pi$ interactions. These will be discussed below. 
Tab. 3: Geometric parameters and symmetry operations for hydrogen bonds and intermolecular interactions $\left(\AA{ }^{\circ}{ }^{\circ}\right)$.

\begin{tabular}{|c|c|c|c|c|c|c|}
\hline & $D-H \cdots A$ & & & $H \cdots A$ & D..A & D-H $\cdots A$ \\
\hline \multicolumn{7}{|c|}{ Intramolecular hydrogen bonds } \\
\hline $2 a$ & $\mathrm{C} 4-\mathrm{H} 4 \cdots 032$ & & & 2.30 & $2.6559(16)$ & 101 \\
\hline 2c & $\mathrm{C} 4-\mathrm{H} 4 \cdots 02$ & & & 2.45 & $2.772(3)$ & 100 \\
\hline \multirow[t]{2}{*}{$2 d$} & $\mathrm{C} 4-\mathrm{H} 4 \cdots 032$ & & & 2.31 & $2.6645(13)$ & 101 \\
\hline & D-H $\cdots A$ & D-H & $H \cdots A$ & D...A & D-H $\cdots A$ & Symmetry code \\
\hline \multicolumn{7}{|c|}{ Intermolecular hydrogen bonds } \\
\hline $2 a$ & $\mathrm{C} 4-\mathrm{H} 4 \cdots \mathrm{O} 2$ & 0.95 & 2.54 & $3.3973(17)$ & 150 & $1 / 2+x, 1-y, z$ \\
\hline $2 a$ & $\mathrm{C} 8-\mathrm{H} 8 \cdots 031$ & 0.95 & 2.51 & $3.4520(18)$ & 171 & $-x,-1 / 2+y, 1 / 2-z$ \\
\hline $2 a$ & $\mathrm{C} 5-\mathrm{H} 5 \cdots 01$ & 0.95 & 2.64 & $3.570(2)$ & 168 & $1 / 2+x, 1-y, z$ \\
\hline $2 b$ & $\mathrm{C} 4-\mathrm{H} 4 \cdots \mathrm{O} 2$ & 0.95 & 2.48 & $3.3951(17)$ & 161 & $x, 1+y, z$ \\
\hline $2 b$ & $\mathrm{C} 71-\mathrm{H} 71 \mathrm{C} \cdots 032$ & 0.98 & 2.59 & $3.555(2)$ & 170 & $1-x, 1-y, 1-z$ \\
\hline $2 b$ & $\mathrm{C} 5-\mathrm{H} 5 \cdots 01$ & 0.95 & 2.50 & $3.200(3)$ & 149 & $x, 1+y, z$ \\
\hline $2 c$ & $\mathrm{C} 5-\mathrm{H} 5 \cdots \mathrm{O} 2$ & 0.95 & 2.50 & $3.200(3)$ & 131 & $x, 1-y, 1 / 2+z$ \\
\hline $2 c$ & С $33-\mathrm{H} 33 \mathrm{~B} \cdots 031$ & 0.99 & 2.55 & $3.510(3)$ & 164 & $1-x, y, 1 / 2-z$ \\
\hline $2 d$ & $\mathrm{C} 4-\mathrm{H} 4 \cdots \mathrm{O} 2$ & 0.95 & 2.54 & $3.4506(14)$ & 161 & $x,-1+y, z$ \\
\hline $2 d$ & C34-H34B $\cdots 031$ & 0.98 & 2.48 & $3.2613(16)$ & 136 & $x,-1+y, z$ \\
\hline \multirow[t]{2}{*}{$2 d$} & $\mathrm{C} 5-\mathrm{H} 5 \cdots 01$ & 0.95 & 2.61 & $3.599(14)$ & 127 & $x,-1+y, z$ \\
\hline & $Y-X \cdots C g$ & $\mathrm{X} \cdots \mathrm{Cg}$ & $\mathbf{X}_{\text {perp }}$ & $\gamma$ & $\mathrm{Y}-\mathrm{X} \cdots \mathrm{Cg}$ & $\mathrm{Y} \cdots \mathrm{Cg}$ \\
\hline
\end{tabular}

$\mathrm{Y}-\mathrm{X} \cdots \pi$ interactions

$\begin{array}{lllllll}2 a & \text { C2-02 } \cdots \text { Cg2 }^{i} & 3.9028(12) & 3.859 & 8.65 & 109.78(9)\end{array}$

Symmetry codes: $\mathrm{i}=-x,-1 / 2+y, 1 / 2-z$.

\begin{tabular}{|c|c|c|c|c|c|c|c|c|}
\hline & $\operatorname{Cg} \mid \cdots \operatorname{Cg}(J)$ & $\mathrm{Cg} \cdots \mathrm{Cg}$ & $\alpha$ & $\beta$ & $\gamma$ & $\mathrm{CgI}_{\text {perp }}$ & $\mathrm{CgJ}_{\text {perp }}$ & Slippage \\
\hline \multicolumn{9}{|c|}{$\pi \cdots \pi$ interactions $^{\mathrm{a}}$} \\
\hline $2 a$ & $\operatorname{Cg} 1 \cdots \operatorname{Cg} 1^{i}$ & $3.9829(8)$ & $0.02(6)$ & 32.9 & 32.9 & $3.3441(5)$ & $3.3441(5)$ & 2.163 \\
\hline $2 a$ & $\operatorname{Cg} 1 \cdots \operatorname{Cg} 2^{i}$ & $3.5446(8)$ & $1.59(6)$ & 21.0 & 19.8 & $3.3360(5)$ & $3.3100(6)$ & 1.268 \\
\hline $2 a$ & $\operatorname{Cg} 2 \cdots \operatorname{Cg} 1^{i}$ & $3.5446(8)$ & $1.59(6)$ & 19.8 & 21.0 & $3.3100(6)$ & $3.3360(5)$ & 1.198 \\
\hline $2 b$ & $\operatorname{Cg} 2 \cdots \operatorname{Cg} 1^{i i}$ & $4.0944(8)$ & $15.47(7)$ & 45.1 & 29.8 & $3.5518(6)$ & $2.8897(6)$ & 2.901 \\
\hline $2 b$ & $\operatorname{Cg} 1 \cdots \operatorname{Cg} 2^{i i i}$ & $4.0944(8)$ & $15.47(7)$ & 29.8 & 45.1 & $2.8897(6)$ & $3.5518(6)$ & 2.037 \\
\hline $2 b$ & $\operatorname{Cg} 1 \cdots \operatorname{Cg} 2^{\text {iv }}$ & $3.7243(8)$ & $4.36(7)$ & 27.3 & 26.0 & $3.3475(6)$ & $3.3081(6)$ & 1.711 \\
\hline $2 b$ & $\operatorname{Cg} 2 \cdots \operatorname{Cg} 1^{\text {iv }}$ & $3.7243(8)$ & $4.36(7)$ & 26.0 & 27.3 & $3.3082(6)$ & $3.3474(6)$ & 1.632 \\
\hline $2 b$ & $\operatorname{Cg} 2 \cdots \operatorname{Cg} 2^{\text {iv }}$ & $3.6368(8)$ & $0.00(7)$ & 25.4 & 25.4 & $3.2841(6)$ & $3.2840(6)$ & 1.563 \\
\hline $2 c$ & $\operatorname{Cg} 1 \cdots \operatorname{Cg} 2^{v}$ & $3.4454(13)$ & $0.70(10)$ & 17.6 & 18.1 & $3.2756(9)$ & $3.2848(9)$ & 1.039 \\
\hline $2 c$ & $\operatorname{Cg} 2 \cdots \operatorname{Cg} 1^{\text {vi }}$ & $3.4454(13)$ & $0.70(10)$ & 18.1 & 17.6 & $3.2849(9)$ & $3.2757(9)$ & 1.068 \\
\hline $2 d$ & $\operatorname{Cg} 1 \cdots \operatorname{Cg} 1^{\text {vii }}$ & $3.5356(7)$ & $6.79(5)$ & 17.4 & 17.4 & $3.3733(4)$ & $3.3733(4)$ & 1.059 \\
\hline $2 d$ & $\operatorname{Cg} 1 \cdots \operatorname{Cg} 2^{\text {vii }}$ & $3.6713(7)$ & $7.16(5)$ & 26.8 & 23.1 & $3.3770(4)$ & $3.2770(5)$ & 1.655 \\
\hline $2 d$ & $\operatorname{Cg} 2 \cdots \operatorname{Cg} 1^{\text {vii }}$ & $3.6714(7)$ & $7.16(5)$ & 23.1 & 26.8 & $3.2771(5)$ & $3.3770(4)$ & 1.440 \\
\hline $2 d$ & $\operatorname{Cg} 2 \cdots \operatorname{Cg} 1^{\text {iv }}$ & $3.4748(7)$ & $3.7014(7)$ & 20.1 & 20.1 & $3.2631(5)$ & $3.2625(4)$ & 1.196 \\
\hline $2 d$ & $\mathrm{Cg} 2 \cdots \operatorname{Cg} 2^{\text {iv }}$ & $3.7014(7)$ & $0.03(5)$ & 27.9 & 27.9 & $3.2721(5)$ & $3.2722(5)$ & 1.730 \\
\hline $2 d$ & $\operatorname{Cg} 1 \cdots \operatorname{Cg} 1^{\text {iv }}$ & $3.4750(7)$ & $0.89(5)$ & 20.1 & 20.1 & $3.2625(4)$ & $3.2632(5)$ & 1.194 \\
\hline
\end{tabular}

${ }^{\mathrm{a}} \alpha$, Dihedral angle between planes I and $\mathrm{J}\left({ }^{\circ}\right) ; \beta$, angle $\mathrm{Cg}(\mathrm{I}) \rightarrow \mathrm{Cg}(\mathrm{J}) ; \gamma$, angle $\mathrm{Cg}(\mathrm{I}) \rightarrow \operatorname{Cg}(\mathrm{J})$ vector and normal to plane $\mathrm{J}\left({ }^{\circ}\right)$; $\mathrm{Cg}-\mathrm{Cg}$, distance between ring centroids $(\AA)$; $C \mathrm{Cg}_{\text {Perp }}$, perpendicular distance of $\mathrm{Cg}(\mathrm{I})$ on ring J $(\AA)$; $\mathrm{Cg} \mathrm{J}_{\text {perp }}$, perpendicular distance of $\mathrm{Cg}(\mathrm{J})$ on ring I $(\AA \AA)$. Symmetry codes: $i=1 / 2-x, 1 / 2-y, 1 / 2-z ; i i=1-x, 1 / 2+y, 3 / 2-z, i i i=1-x,-1 / 2+y, 3 / 2-z ; i v=1-x, 1-y, 1-z ; v=x,-1+y, z ; v i=x, 1+y, z$;

$v i i=1-x, y, 1 / 2-z$.

Tab. 4: Percentages for the most relevant atom-atom contacts for the studied compounds (\%).

\begin{tabular}{|c|c|c|c|c|c|c|}
\hline & $\mathrm{H} \cdots \mathrm{H}$ & $\mathrm{H} \cdots \mathrm{O} / 0 \cdots \mathrm{H}$ & $\mathrm{H} \cdots \mathrm{C} / \mathrm{C} \cdots \mathrm{H}$ & $c \cdots c$ & $c \cdots 0 / 0 \cdots c$ & $0 \cdots 0$ \\
\hline $2 a$ & 40.3 & 31.0 & 15.7 & 6.2 & 5.0 & 1.8 \\
\hline $2 b$ & 37.9 & 36.8 & 16.9 & 6.0 & 2.1 & 0.4 \\
\hline $2 c$ & 43.9 & 30.2 & 13.7 & 7.9 & 3.3 & 1.1 \\
\hline $2 d$ & 39.6 & 36.9 & 6.8 & 11.2 & 4.0 & 1.6 \\
\hline
\end{tabular}




\section{Chain formation utilizing $\mathrm{C}-\mathrm{H}-\mathrm{O}$ hydrogen bonds, utilizing the carbonyl 02 oxygen}

In each of the four compounds, chains of molecules are formed from $\mathrm{C}-\mathrm{H} \cdots \mathrm{O}$ hydrogen bonds, utilizing, at least, the 02(carbonyl oxygen) atom. In $\mathbf{2 a}$ and $\mathbf{2 b}$, the molecular chains are generated from $\mathrm{C} 4-\mathrm{H} 4 \cdots 02$ and $\mathrm{C} 5-\mathrm{H} 5 \cdots \mathrm{O} 1$ (pyran) hydrogen bonds, thereby providing $\mathrm{C} 5, \mathrm{C} 5, \mathrm{R}_{2}^{2}(8)$ chains [55], while in compound 2d, additional $\mathrm{C} 34-\mathrm{H} 34 \mathrm{~B} \cdots 031$ (ester) hydrogen bonds result in a more complex $\mathrm{C} 5, \mathrm{C} 5, \mathrm{C} 6, \mathrm{R}_{2}^{2}(8) \mathrm{R}_{2}^{2}(13)$ arrangement [55], see Figure 5. The zig-zag chains in

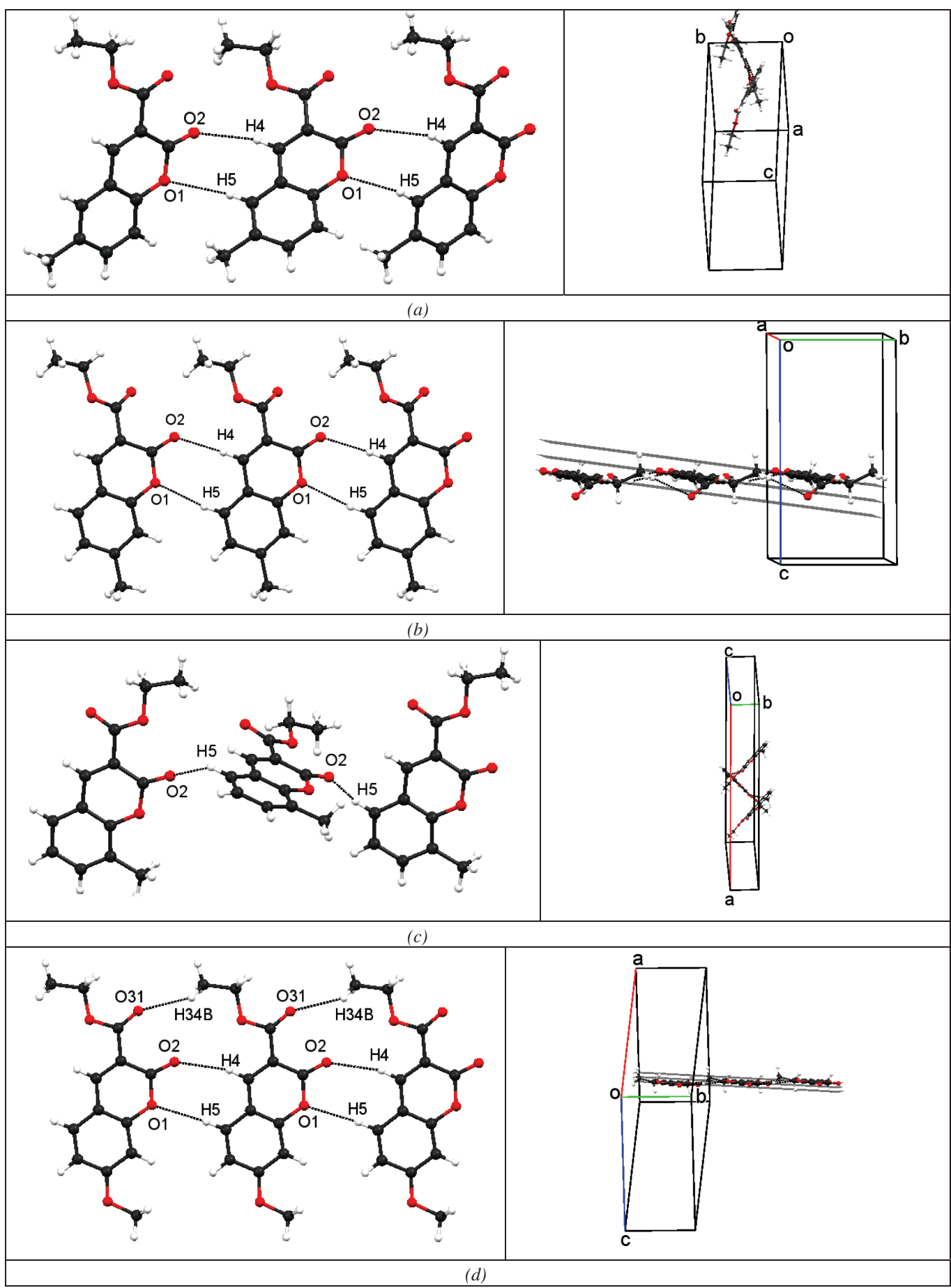

Fig. 5: Two views of the molecular chains in (a) $\mathbf{2 a}$, (b) $\mathbf{2 b}$, (c) $\mathbf{2 c}$ and (d) $\mathbf{2 d}$. Intermolecular interactions are drawn as dashed lines. Table 3 lists the symmetry codes for the intermolecular interactions. 
$\mathbf{2 a}$ are propagated in the direction of the $c$ axis, while in $\mathbf{2} \mathbf{b}$ and $\mathbf{2 d}$, the chains are propagated in the direction of the $b$ axis, with the coumarin cores in adjacent molecules parallel but separated by perpendicular distances of 0.86 and $0.42 \AA$, respectively in $\mathbf{2 b}$ and $\mathbf{2 d}$, see Figure $5 \mathrm{~b}$ and $\mathrm{d}$.

In compound $\mathbf{2 c}$, the chains, $\mathrm{C}$, of molecules are obtained solely from $\mathrm{C} 5-\mathrm{H} 5 \mathrm{~B} \cdots \mathrm{O} 2$ hydrogen bonds and are thus very different from the chains in $\mathbf{2 a}, \mathbf{2} \mathbf{b}$ and $\mathbf{2 d}$. The absence of $\mathrm{C} 4-\mathrm{H} 4 \cdots \mathrm{O} 2$ and $\mathrm{C} 5-\mathrm{H} 5 \cdots 01$ hydrogen bonds in 2c follows from the large $\mathrm{H} 4-\mathrm{O} 2$ and $\mathrm{H} 5 \mathrm{~B}-\mathrm{O} 1$ distances of 2.834 and $4.428 \AA$, respectively. Successive molecules in the chain are near orthogonal, with an interplanar angle of $89.91^{\circ}$, see Figure $5 \mathrm{c}$.

It is argued that if $\mathbf{2 c}$ produced a similar chain to those found in $\mathbf{2 b}$ and $\mathbf{2 d}$, it would result in severe steric hindrance between the C8-methyl group and to a C61-hydrogen in an adjacent molecule. The shortest C $\cdots$ H61 separations are 2.814 and $2.873 \AA$, respectively in $\mathbf{2 b}$ and $\mathbf{2 d}$. However, the reverse situation with Me on C61 and H8 on C8, does not prevent chain formation in compound 2a: the $\mathrm{H} 8-\mathrm{H} 61 \mathrm{C}$ distance in $\mathbf{1}$ is $2.655 \AA$ Anterestingly, the 01 ring oxygen is not utilized in any intermolecular interaction in 2c. The lack of $\mathrm{C} 4-\mathrm{H} 4 \mathrm{vO} 32$ hydrogen bonds in $\mathbf{2 b}$ apparently arises from the larger rotation of the $\mathrm{C}(\mathrm{O}) \mathrm{OEt}$ group out of the coumarin plane, which results in a too

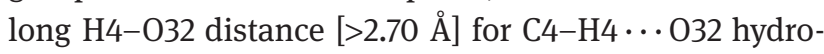
gen bonding.

\section{Other intermolecular interactions}

\section{Compound 2a}

Other intermolecular interactions present in $\mathbf{2 a}$ are $\mathrm{C} 8-\mathrm{H} 8 \cdots 031$ hydrogen bonds, $\mathrm{C}=\mathrm{O} \cdots \pi$ and $\pi \cdots \pi$ interactions, see Table 4. The combinations of these additional interactions generate chains, two of which pass though the unit cell, as shown in Figure 6a. The overlap of the $\pi$ systems in the chain, shown in Figure $6 \mathrm{~b}$, involves both rings and with a perpendicular distance of $3.317 \AA$ between parallel coumarin cores, this is clearly an important interaction. The Hirshfeld surfaces for $\mathbf{2 a}$ are shown in Supplementary Figure 2.

\section{Compound 2b}

As well as the $\mathrm{C} 4-\mathrm{H} 4 \cdots \mathrm{O} 2$ and $\mathrm{C} 5-\mathrm{H} 5 \cdots \mathrm{O} 1$ hydrogen bonds, other intermolecular interactions identified in $\mathbf{2 b}$ are a $\mathrm{C} 71-\mathrm{H} 71 \mathrm{C} \cdots \mathrm{O} 32$ hydrogen bond and $\pi \cdots \pi$ interactions, see Table 3 and Figure 7 . There are two distinct $\pi \cdots \pi$ stacking interactions, which generate chains, see Figure 7 . The stronger of the two $\pi \cdots \pi$ interactions, $\pi \cdots \pi^{\mathrm{i}}$, is augmented by $\mathrm{C} 71-\mathrm{H} 71 \mathrm{C} \cdots \mathrm{O}^{\mathrm{i}}$ hydrogen bonds; and has a $\mathrm{Cg}$ (coumarin) $-\mathrm{Cg}$ (coumarin) separation of 3.6368(8) $\AA$, and a strong overlap of the $\pi$ systems, see Figure $7[i=1-x, 1-y, 1-z]$. The second

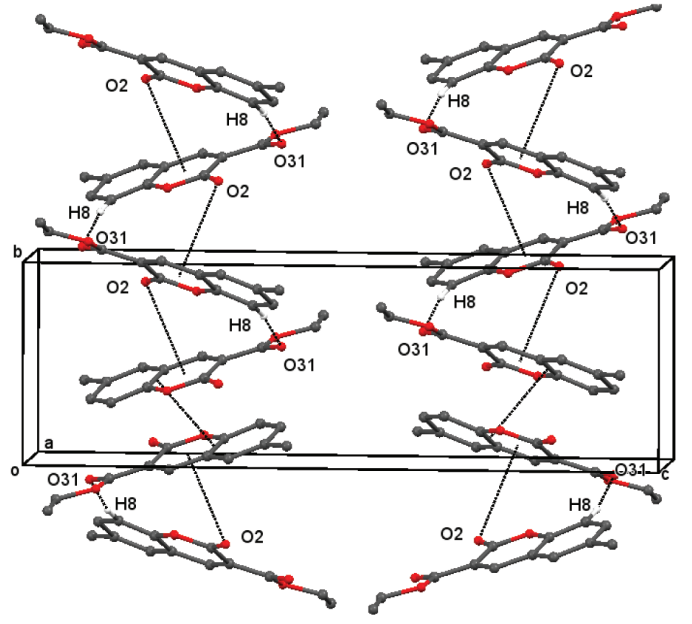

(a)

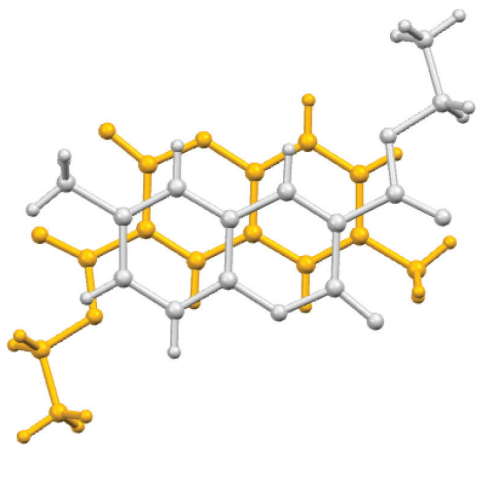

(b)

Fig. 6: Compound 2a. (a) Parts of two single molecular-wide chains of molecules, passing through the unit cell, derived from combinations of $\mathrm{C} 8-\mathrm{H} 8 \cdots 031$ hydrogen bonds, $\mathrm{C}=\mathrm{O} \cdots \pi$ (pyran) and $\pi$ (coumarin) $\cdots \pi$ (coumarin) interactions, (b) the view of the overlap of the interacting $\pi$ systems in the $\pi \cdots \pi$ interactions. Intermolecular interactions are drawn as dashed lines. Table 3 lists the symmetry codes for the intermolecular interactions. 


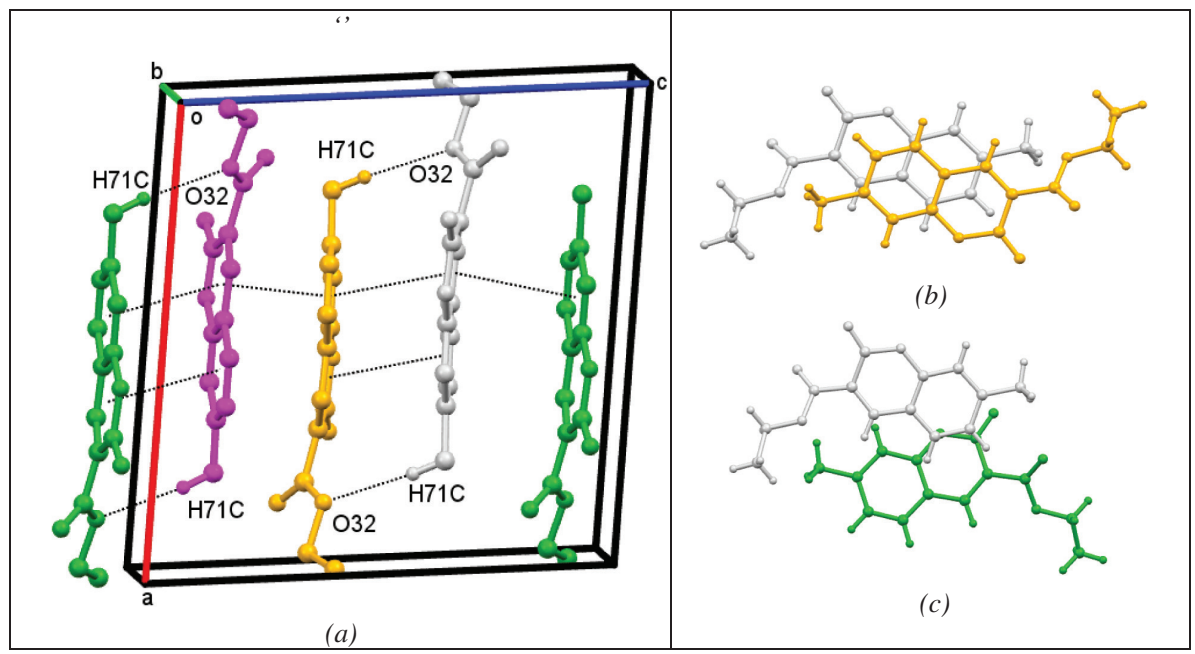

Fig. 7: Compound 2b. (a) Part of the column of molecules, coloured according to symmetry codes, generated from combinations of C71-H71C-032 hydrogen bonds, and $\pi \cdots \pi^{\mathrm{i}}$ and $\pi \cdots-\pi^{\mathrm{i}}$ interactions: symmetry codes: $\mathrm{i}=1-\mathrm{x}, 1-\mathrm{y}, 1-\mathrm{z} ; \mathrm{ii}=1-\mathrm{x},-1 / 2+\mathrm{y}, 3 / 2-\mathrm{z}$, (b) and (c) illustrates the $\pi$ overlaps in the $\pi \cdots \pi$ stacks shown in Figure $7 a$. Intermolecular interactions are drawn as dashed lines. Table 3 lists the symmetry codes for the intermolecular interactions.

interaction, $\pi \cdots \pi^{\mathrm{ii}}$, has a much reduced $\pi$ overlap, with a longer $\mathrm{Cg}-\mathrm{Cg}$ separation of 4.0944(8) $\AA$, see Figure $7 \mathrm{~b}$ and c: symmetry operation: $\mathrm{ii}=1-\mathrm{x},-1 / 2+\mathrm{y}, 3 / 2-\mathrm{z}$. As reported earlier, the EtOC(O) unit is out of the plane of its attached coumarin core. A consequence of this is that the distance between $\mathrm{H} 71 \mathrm{C}$ and $032^{\mathrm{i}}$ is sufficiently short to allow the formation of $\mathrm{C} 71-\mathrm{H} 71 \mathrm{C} \cdots \mathrm{O} 32$ hydrogen bonds. The Hirshfeld surface for $\mathbf{2} \mathbf{b}$ is shown in Supplementary Figure 3.

\section{Compound 2c}

The additional intermolecular interactions in $\mathbf{2 c}$ are C33H33B $\cdots 031$ hydrogen bonds and $\pi \cdots \pi$ interactions, which combine to form the chevron-shaped sub-structure, shown in Figure $8 \mathrm{a}$ and $\mathrm{b}$. The arrangement can be considered as being made up from symmetric dimers, formed from pairs of C33-H33B $\cdots$ O31 hydrogen bonds, which are then linked via $\pi \cdots \pi$ interactions into the chevron array.
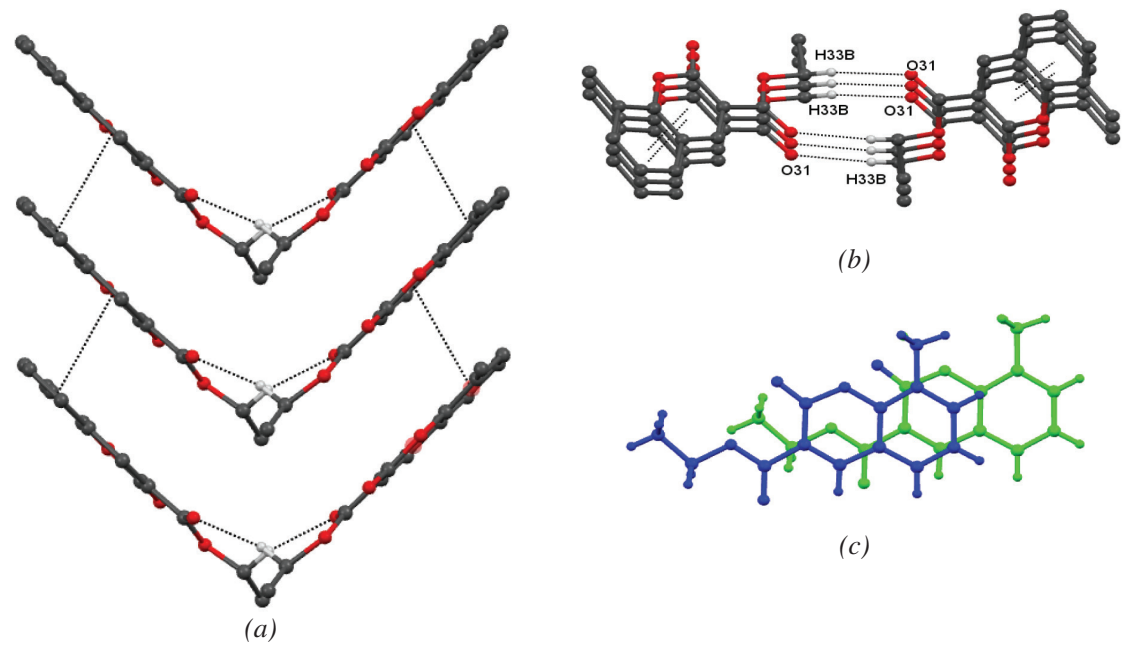

(b)

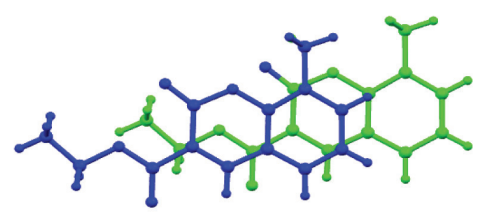

(c)

Fig. 8: Compound 2c. (a) and (b) Two views of the chevron-type arrangement of molecules generated from C33-H33B …031 hydrogen bonds and $\pi \cdots \pi$ interactions: within this arrangement are $\mathrm{R}_{2}^{2}(10)$ rings, better seen in Figure $8 \mathrm{~b}$, (c) the overlap of the $\pi$ systems in the $\pi \cdots \pi$ stacks. Intermolecular interactions are drawn as dashed lines. Table 3 lists the symmetry codes for the intermolecular interactions. 
The angle between the coumarin units in the chevron is near orthogonal, at $89.79^{\circ}$. The overlap of the $\pi$ systems is extensive as shown in Figure 8c, and with a perpendicular distance between the parallel coumarin units in the $\pi \cdots \pi$ stack of only $3.281 \AA$ - this interaction appears a critical one.

The Hirshfeld surface for $\mathbf{2 c}$ is shown in Supplementary Figure 4.

\section{Compound 2d}

The additional intermolecular interactions in $\mathbf{2 d}$ are two distinct $\pi \cdots \pi$ interactions, $\pi \cdots \pi^{\mathrm{i}}$ and $\pi \cdots \pi^{\mathrm{ii}}$, which alternate to form stacks of molecules: symmetry codes: $i=1-x, y, 1 / 2-z$ and $i i=1-x, 1-y, 1-z$, see Figure 9a. The orientation of the molecules alternates in successive rows of the stack. The distance between the best planes through parallel coumarin cores in the $\pi \cdots \pi^{\mathrm{ii}}$ interactions is 3.2721(5) A. Due to the coumarin cores in the $\pi \cdots \pi^{\mathrm{i}}$ interaction not being parallel, the equivalent distance varies between 3.27 and $3.37 \AA$, with good overlaps of the $\pi$ systems, see Figure $9 \mathrm{~b}$ and $\mathrm{c}$. Thus, both $\pi \cdots \pi$ interactions appear important interactions. These $\pi \cdots \pi$ stacks are linked primarily by the three $\mathrm{C}-\mathrm{H} \cdot \mathrm{OO}$ hydrogen bonds, namely $\mathrm{C} 4-\mathrm{H} 4 \cdots \mathrm{O} 2$, $\mathrm{C} 5-\mathrm{H} 5 \cdots \mathrm{O} 1$ and $\mathrm{C} 34-$ H34B $\cdots 031$ hydrogen bonds, shown in Figure 5d, into a three dimensional array. In addition there is the possibility of further support from a weak C34-H34A $\cdots \mathrm{O}^{\mathrm{i}}$ hydrogen bond, with parameters $d(\mathrm{H} 34 \mathrm{~A}-07)=2.62 \AA$, $\mathrm{C} 34-\mathrm{H} 34 \mathrm{~A} \cdots \mathrm{O} 7$ angle $=163^{\circ}$ and symmetry code: $\mathrm{i}=1 / 2+\mathrm{x}, 1 / 2-\mathrm{y}, 1 / 2+\mathrm{z}$.
The Hirshfeld surface for $\mathbf{2 d}$ is shown in Supplementary Figure 5.

\section{Finger print (FP) plots}

The FP plots for all compounds, shown in Figure 10, exhibit two pairs of spikes pointing south-west $\left(d_{e}\right.$, $\left.\mathrm{d}_{\mathrm{i}}\right) \cong(1.4,1.0) \AA$, corresponding to $\mathrm{H} \cdots \mathrm{O}$ close contacts and a light blue area spread around $\mathrm{d}_{\mathrm{e}} \cong \mathrm{d}_{\mathrm{i}} \cong 1.8 \AA$ that is due to $\mathrm{C}$... C close contacts. The areas with higher intensity of pixels spread around $\mathrm{d}_{\mathrm{e}} \cong \mathrm{d}_{\mathrm{i}} \cong 1.6 \AA$ are due to $\mathrm{H} \cdot \mathrm{H}$ contacts. Of the three isomers, compounds $\mathbf{2} \mathbf{a}-\mathbf{2} \mathbf{c}, \mathbf{2} \mathbf{b}$ has the highest percentage sum of all oxygen close contacts, and $2 \mathrm{c}$ the highest percentages of $\mathrm{H} \cdot \mathrm{H}$. contacts. Compound, $\mathbf{2 d}$, with the additional oxygen atom, has the highest percentage sum of all oxygen contacts, the highest percentage of $\mathrm{C} \cdots \mathrm{C}$ contacts and the lowest percentage of $\mathrm{C} \cdot \mathrm{H} / \mathrm{H} \cdot \mathrm{C}$ contacts, of all four compounds. Compound 2d has a higher percentage of $\mathrm{C} \cdots \mathrm{C}$ and $\mathrm{C} \cdots \mathrm{H} / \mathrm{H} \cdots \mathrm{C}$ contacts than does $\mathbf{2 b}$, see the light blue area spread around $\mathrm{d}_{\mathrm{e}} \cong \mathrm{d}_{\mathrm{i}} \cong 1.6 \AA$.

\section{Comparisons of reported solid state molecular conformations of alkyl $2 \mathrm{H}$-chromene-3-carboxylates}

A survey of the CCDC data base for organyl $2 \mathrm{H}$-chromene3-carboxylates on Jun 22nd, 2017 [56] revealed 61 hits, of which ca. 50 compounds were unique and had sufficient deposited data to enable distances and angles to

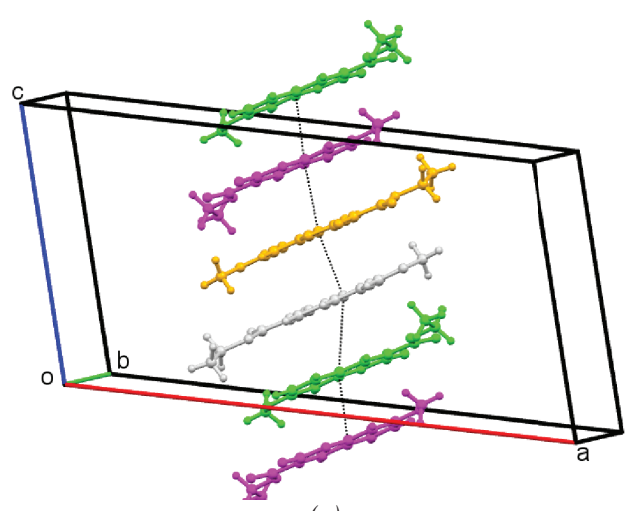

(a)

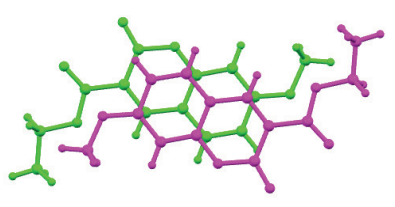

(b)

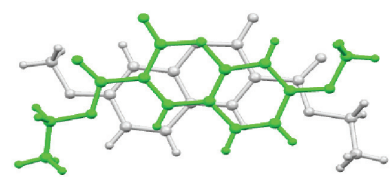

(c)

Fig. 9: Compound 2d. (a) Part of a $\pi \cdots \pi$ stack formed from alternating, $\pi \cdots \pi^{\mathrm{i}}$ and $\pi \cdots \pi^{\mathrm{i} i}$ interactions: symmetry codes: $i=1-x, y, 1 / 2-z$ and $\mathrm{ii}=1-\mathrm{x}, 1-\mathrm{y}, 1-\mathrm{z}$; the molecules are coloured according to symmetry operations, (b) and (c) overlaps of the $\pi$ systems in the $\pi \cdots \pi^{i}$ and $\pi \cdots \pi^{\mathrm{ii}}$ interactions. Intermolecular interactions are drawn as dashed lines. Table 3 lists the symmetry codes for the intermolecular interactions. 


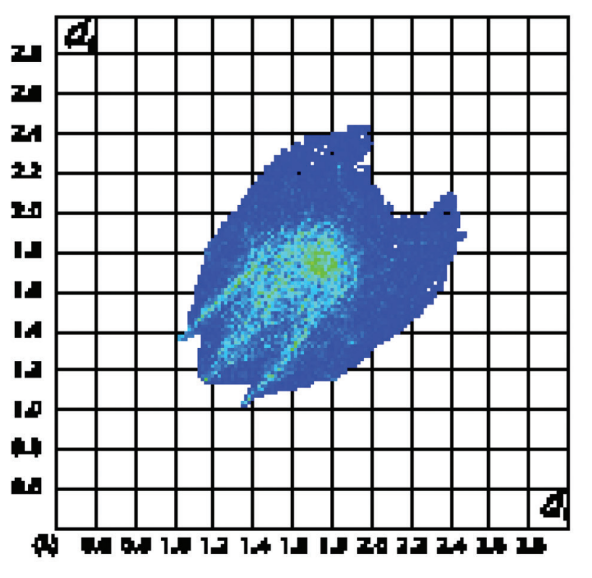

$2 \mathbf{a}$

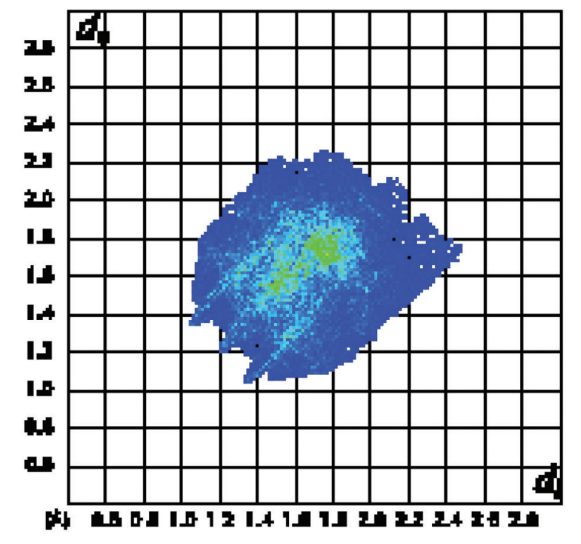

2c

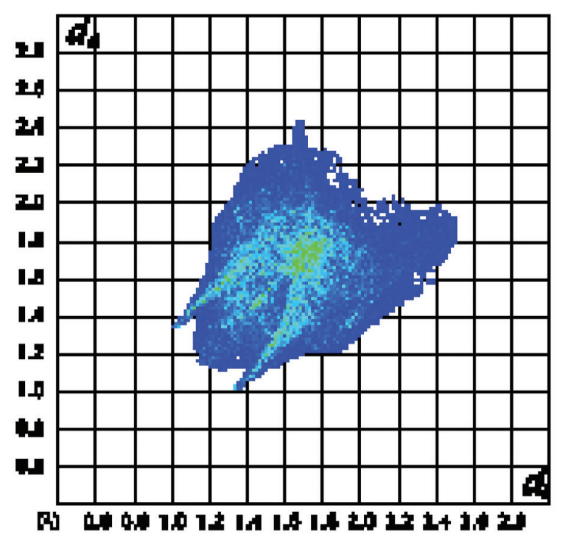

2b

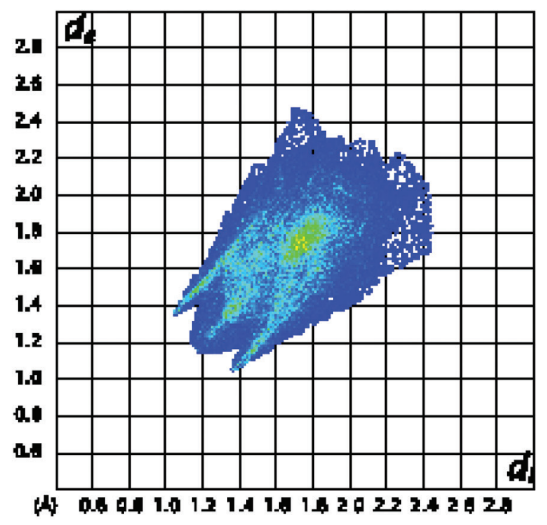

2d

Fig. 10: The FP plots for $\mathbf{2 a - 2 d}$. The southwest spikes ending at $\left(\mathrm{d}_{\mathrm{e}}, \mathrm{d}_{\mathrm{i}}\right) \cong(1.4,1.0) \AA$ are present in all the plots and are due to the $\mathrm{C}-\mathrm{H} \ldots \mathrm{O}$ hydrogen bonds: the light blue area around $\mathrm{d}_{\mathrm{e}} \cong \mathrm{d}_{\mathrm{i}} \cong 1.8 \AA$ is present in all structures and indicate $\mathrm{C} \cdots \mathrm{C}$ close contacts. The plot for compound $2 \mathrm{~d}$ also presents a light blue area around $\mathrm{d}_{\mathrm{e}} \cong \mathrm{d}_{\mathrm{i}} \cong 1.6 \AA$, due to $\mathrm{H} \cdots \mathrm{H}$ contacts.

be obtained. The substituents in the coumarin moiety and the carboxylate unit, both alkyl and aryl, varied greatly in terms of steric bulk and electronic effects. With the numbering scheme adopted in this study, see Figure 2, values have been obtained for the C4-C3-C31$\mathrm{O} 31$ and $\mathrm{C} 4-\mathrm{C} 3-\mathrm{C} 31-\mathrm{O} 32$ torsion angles, interplanar angles between the coumarin core and the $\mathrm{C} 3,031,032$, C32 atoms of the carboxylate side chain and the distance between the two carbonyl oxygen atoms, $\mathrm{O} 2$ and 031 . Aspects of these geometric parameters will be discussed here, whilst fuller details are provided in Supplementary Table 1.

Without constraints such as the intramolecular $\mathrm{N}-\mathrm{H}$ (amido) $\cdots \mathrm{O}$ (carbonyl) hydrogen bonds found in the 2H-chromene-3-carboxamides [39, 40], values of the angles between the coumarin core and the carboxylate side chains vary between $0.00^{\circ}$, in dimethyl 4-(8-t-butyl-3-(methoxycarbonyl)-2-oxo-2H-chromen-6-yl)- 2,6-dimethyl-1,4-dihydropyridine-3,5-dicarboxylate, 2e, (Ref. [57]: CCDC codes: GIGDOR; 877578), to $60.73^{\circ}$, in the $P 2_{1} / n$ phase of ethyl 8-methoxy-2-oxo-2H-1-benzopyran-3-carboxylate, $\mathbf{2 f}$ (Ref. [58]: CCDC codes: ADAZUB: 610860), see Figure 1. The large majority of the compounds have interplanar angles of $<20^{\circ}$. Even in related compounds, such angles can be very different, e.g. the interplanar angle, $60.73^{\circ}$, in $\mathbf{2 f}$, which was recrystallised from $\mathrm{CHCl}_{3}$, is very different from that of its ethoxy analogue, $\mathbf{2 g}$ (Ref. [59]: CCDC codes: EYIJUT: 1447837), recrystallised from $\mathrm{MeOH}$, as well as that found in its co-crystal with 2-aminobenzothiazole, (Ref. [60]: GUFDOB: 672097), values being $14.20(8)$ and $4.48(8)^{\circ}$, respectively.

It is interesting to compare the dihedral angles and 02-031 distances in the simple alkyl 2H-chromene3-carboxylates, having no substituent in the phenyl ring of the coumarin moiety, thereby attempting to eliminate potential steric effects of ring substituents, see Table $5 a$. 
Tab. 5: Values of $\mathrm{d}\left(\mathrm{O}_{2}-\mathrm{O}_{31}\right)$ and the $\mathrm{C} 4-\mathrm{C} 3-\mathrm{C} 31-031$ torsional angles in published organyl $2 \mathrm{H}$-chromene-3-carboxylate structures.

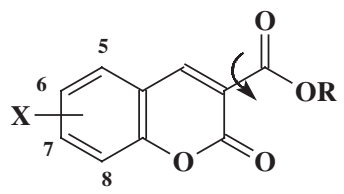

\begin{tabular}{|c|c|c|c|c|c|c|c|c|c|}
\hline $\mathbf{R}$ & $\mathrm{C} 4-\mathrm{C}_{3}-\mathrm{C}_{3}$ & $31^{\circ}$ & $\mathrm{d}\left(\mathrm{O}_{2}\right.$ & & & trans & & $\mathrm{CCDC} C \mathrm{C}$ & \\
\hline (a) Alkyl $2 \mathrm{H}$-chrom & e-3-carboxy &,$(X=H)$ & & & & & & & \\
\hline Me & & 4(2) & & & & & & CEHGU & 6978 \\
\hline Et & -16 & (14) & 2.79 & & $c i$ & & & MURCU & 011994 \\
\hline i-Pr & 17 & (10) & 2.84 & & & & & ILICOX: & 8007 \\
\hline & -17 & (12) & 2.85 & & & & & & \\
\hline$t-B u$ & & $0(2)$ & & & & to trans & & JELYOP: & 583 \\
\hline & & & & $\left.{ }_{31}\right)<3.0 \AA^{*}$ & & & & $\mathrm{~d}\left(\mathrm{O}_{2}\right.$ & )$>3.9 \AA$ \\
\hline (b) All organyl $2 \mathrm{H}$ - & omene-3-ca & ylate deriv & & & & & & & \\
\hline$C_{4}-C_{3}-C_{31}=O_{31}^{\circ}$ & $130-150$ & $150-160$ & $160-170$ & $170-180$ & $0-10$ & $10-20$ & $20-30$ & $30-40$ & $40-50$ \\
\hline No. of molecules & 5 & 5 & 11 & 12 & 11 & 6 & 5 & 0 & 2 \\
\hline Total & & & & 33 & & & & & 24 \\
\hline
\end{tabular}

*The numbering scheme is that used in this article.

No trend in the geometric parameters with the bulk of the R group is apparent.

The designation of a $s$-cis or a s-trans form for each compound was primarily obtained from the $02-031$ distance: values less than $3 \AA$ clearly have $s$-cis forms and those greater than $4 \AA$ have s-trans-forms. Values of torsional angles can also be used, e.g. values of the torsional angle, $\mathrm{C} 4-\mathrm{C} 3-\mathrm{C} 31-\mathrm{O} 31^{\circ}$, angles greater than $150^{\circ}$ or less than $30^{\circ}$ are clearly indicators of $s$-cis and s-trans forms, respectively. There are some compounds exhibiting intermediate values, e.g. 8-methoxy-2H-chromene-3-carboxylate [CCDC codes: ADAZUB: 610860] has C4-C3-C31O31 and d(02-031) values of $-121.89(15)^{\circ}$ and $3.0865 \AA$, respectively.

The distance between the two carbonyl oxygen atoms, $\mathrm{O} 2$ and 031, range from 2.773(3) (Ref. [61]: CCDC codes: PUGSAM 754378) to 4.329(2) ^ (Ref. [62]: CCDC codes: XOTRAB; 996298), see the Supplementary Table 2. There are two distinctly popular ranges, namely 4.094(2)4.329(2) (s-trans compounds) and 2.777(3) - $3 \AA$ (s-cis compounds). As shown in Table $5 \mathrm{~b}$, there is just a slight excess of compounds having the shorter 02-031 distances. This is in agreement with the theoretical M06-2X/study on the simple compounds, $\mathbf{2 a - 2 d}$, which showed that the A and $B$ forms, have very similar stabilities, but with a slight preference for the A form. Interestingly, in $(2 R, 3 R)$-diethyl tartrate 2,3-bis(7-diethylaminocoumarin-3-carboxylate), 2h, see Figure 1, (Ref. [63]: CCDC codes: OKIRIJ: 154949), the two carboxylate units have different orientations w.r.t. their attached coumarin moieties, with $02-031$ distances of 2.848(9) and 4.184(9) $\AA$.

\section{Conclusions}

The theoretical and the crystallographic study of the four ethyl 2H-chromene-3-carboxylate derivatives and the survey of the published literature on organyl $2 \mathrm{H}$-chromene-3-carboxylates led to the same conclusion that the favoured conformations had the ester chain near planar to the coumarin cores.

Theoretical calculations of the molecular conformations in methanol of the four ethyl $2 \mathrm{H}$-chromene-3-carboxylate derivatives indicated only small differences in energies (at most $<0.5 \mathrm{KJ} / \mathrm{mol}$ ) between the $s$-cis and $s$-trans forms, with the $s$-cis form being the more favoured in $\mathbf{2 a - 2 c}$ and equal stabilities for the two forms of $\mathbf{2 d}$. Rotations of the ester group out the coumarin plane resulted in a Gaussian distribution of stabilities with the maximum energy occurring at around $90^{\circ}$. Rotations about the $\mathrm{C}-\mathrm{C}$ bond of the ester ethyl group in all four molecules and about the $\mathrm{O}-\mathrm{C}$ bond of the 7-methoxyl substituent in $\mathbf{2 d}$ were calculated to affect the energies as well, with extended forms leading to greater stability. The solid state molecular conformations of compounds $\mathbf{2 a}$ (s-cis form), 2c (s-trans form) and $\mathbf{2 d}$ (cis form) were close to the calculated low energy forms: differences arose from the small interplanar angles of 10.41(6), 10.4(2) and $5.64(6)^{\circ}$, respectively. A greater rotation of the ester group by $36.65(6)^{\circ}$ in $\mathbf{2 b}$, resulted in a greater difference between the experimental and calculated structures. The survey of organyl 2H-chromene-3-carboxylate compounds indicated two distinct groupings: $s$-trans compounds, with carbonyl oxygen-carbonyl distances of 4.094(2)-4.329(2) $\AA$ and 
interplanar angles less than $30^{\circ}$ and s-cis compounds with equivalent parameters of $2.777(3)-3 \AA$ and angles greater than $150^{\circ}$. Very few compounds had intermediate values.

The Hirshfeld surface and PLATON analysis confirmed the presence in $\mathbf{2 a - 2 d}$ of (i) $\mathrm{C}-\mathrm{H} \cdots \mathrm{O}$ hydrogen bonds, which lead primarily to molecular chains, and (ii) $\pi \cdots \pi$ interactions, which provide molecular dimers and stacks.

\section{Supplementary material}

Supplementary Figure 1 shows all the calculated conformations, $A-G$, for compounds $\mathbf{2 a - 2 d}$ and their energies, Supplementary Figures 2-5 show the Hirshfeld surfaces of compounds $\mathbf{2 a - 2 d}$, respectively and Supplementary Table 1 lists information on conformations of $2 \mathrm{H}$-chromene-3-carboxylate derivatives.

Full details of the crystal structure determinations in cif format are available in the online version, at https:// doi.org/10.1515/zkri-2018-2117. The cif-files have also been deposited with the Cambridge Crystallographic Data Centre with deposition numbers 1573018-1573021 for compounds $\mathbf{2 b}, \mathbf{2 c}, \mathbf{2 a}$ and $\mathbf{2 d}$, respectively, copies of which can be obtained free of charge on written application to CCDC, 12 Union Road, Cambridge, CB2 1EZ, UK (fax: +44 1223 336033); on request by e-mail to deposit@ccdc. cam.ac.uk or by access to http://www.ccdc.cam.ac.uk.

Acknowledgements: The authors thank the National Crystallographic Service, University of Southampton, UK, for the data collection, and for their help and advice. LRG thanks the Portuguese Foundation for Science and Technology (FCT) UID/Multi/04546/2013 for support. TvM is grateful to EaStCHEM for computational support via the EaStCHEM Research Computing Facility. JLW thanks CNPq, Brazil for support.

\section{References}

[1] M. Costa, T. A. Dias, A. Brito, F. Proenca, Eur. J. Med. Chem. 2016, 123, 487.

[2] E. C. Gaudino, S. Tagliapietra, K. Martina, G. Palmisano, G. Cravotto, RSC Adv. 2016, 6, 46394.

[3] H. Wei, J. Ruan, X. Zhanga, RSC Adv. 2016, 6, 846.

[4] B. J. Connell, S.-Y. Chang, E. Prakash, R. Yousfi, V. Mohan, W. Posch, D. Wilflingseder, C. Moog, E. N. Kodama, P. Clayette, PLoS One 2016, 11, e0165386.

[5] D. Yu, M. Suzuki, L. Xie, S. L. Morris-Natschke, K.-H. Lee, Med. Res. Rev. 2003, 23, 322.

[6] S. K. Yusufzai, H. H. Osman, M. S. Khan, S. Mohamad, O. Sulaiman, T. Parumasivam, J. A. Gansau, N. Johansah, Noviany, Med. Chem. Res. 2017, 26, 1139.
[7] G. X. Pang, C. Niu, N. Mamat, H. A. Aisa, Bioorg. Med. Chem. Lett. 2017, 27, 2674.

[8] J. Suthiwong, Y. Thongsri, C. Yenjai, Nat. Prod. Res. 2017, 31, 453.

[9] G. Kirsch, A. B. Abdelwahab, P. Chaimbault, Molecules 2016, $21,322$.

[10] V. T. Angelova, V. Valcheva, N. G. Vassilev, R. Buyukliev, G. Momekov, I. Dimitrov, L. Saso, M. Djukic, B. Shivachev, Bioorg. Med. Chem. Lett. 2017, 27, 223.

[11] R. S. Keni, B. S. Sasidhar, B. M. Nagaraja, M. A. Santos, Eur. J. Med. Chem. 2015, 100, 257.

[12] S. Vazquez-Rodriguez, R. F. Guíñez, M. J. Matos, C. Olea-Azar, J. D. Maya, E. Uriarte, L. Santana, Med. Chem. 2016, 12, 537.

[13] R. Pingaew, A. Saekee, P. Mandi, C. Nantasenamat, S. Prachayasittikul, S. Ruchirawa, V. Prachayasittikul, Eur. J. Med. Chem. 2014, 85, 65.

[14] P. Jithin Raj, D. Bahulayan, Tetrahedron Lett. 2017, 58, 2122.

[15] A. Skoczynska, M. Małecka, M. Cieslak, J. Kazmierczak-Baranska, K. Krolewska-Golinska, A. Leniart, E. Budzisz, Polyhedron 2017, 127, 307.

[16] J. Dandriyal, R. Singla, M. Kumar, V. Jaitak, Eur. J. Med. Chem. 2016, 119, 141.

[17] G. E. Escudero, C. H. Laino, G. A. Echeverría, O. E. Piro, N. Martini, A. N. Rodríguez, J. J. M. Medina, L. L. Tévez, E. G. Ferrer, P. A. M. Williams, Chem. Bio. Interactions 2016, 249, 46.

[18] A. Montagut-Romans, M. Boulven, M. Jacolot, S. MoebsSanchez, C. Hascoët, A. Hammed, S. Besse, M. Lemaire, E. Benoit, V. Lattard, F. Popowycz, Bioorg. Med. Chem. Lett. 2017, $27,1598$.

[19] G. Wang, J. Wang, D. He, X. Li, J. Li, Z. Peng, Chem. Bio. Drug. Des. 2017, 89, 456.

[20] I. Hueso-Falcón, Á. Amesty, L. Anaissi-Afonso, I. Lorenzo Castrillejo, F. Machín, A. Estévez, Bioorg. Med. Chem. Letts. 2017, $27,484$.

[21] J. Joubert, G. B. Foka, B. P. Repsold, D. W. Oliver, E. Kapp, S. F. Malan, Eur. J. Med. Chem. 2017, 125, 853.

[22] S. Hamulakova, M. Kozurkova, K. Kuca, Curr. Org. Chem. 2017, 21, 502.

[23] M. J. Matos, S. Vazquez-Rodriguez, A. Fonseca, E. Uriarte, L. Santana, F. Borges, Curr. Org. Chem. 2017, 21, 311.

[24] M. J. Matos, P. Janeiro, R. M. F. Gonzalez, S. Vilar, N. P. Tatonetti, L. Santana, E. Uriarte, F. Borges, J. A. Fontenla, D. Vina, Future Med. Chem. 2014, 6, 371.

[25] S. R. Trenor, A. R. Shultz, B. J. Love, T. E. Long, Chem. Rev. 2004, 104, 3059.

[26] Ş. N. K. Elmas, F. Ozen, K. Koran, I. Yilmaz, A. O. Gorgulu, S. Erdemir, J. Fluorescence 2017, 27, 463.

[27] H. T. Srinivasa, H. N. Harishkumar, B. S. Palakshamurthy, J. Mol. Struct. 2017, 1131, 97.

[28] W. H. Perkin, J. Chem. Soc. 1868, 21, 181.

[29] H. Pechmann, C. Duisberg, Ber. Dtsch. Chem. Ges. 1884, 17, 929.

[30] E. Knoevenagel, Ber. Dtsch. Chem. Ges. 1904, 37, 4461.

[31] P.-H. E. Yao, S. Kumar, Y.-L. Liu, C.-P. E. Fang, C.-C. Liu, C.-M. Sun, Comb. Sci. 2017, 19, 271.

[32] P. Priyanka, R. K. Sharma, D. Katiyar, Synthesis 2016, 48, 2303.

[33] R. Pratap, V. J. Ram, Tetrahedron 2017, 73, 2529.

[34] L. S. da S. Pinto, M. V. N. de Souza, Synthesis 2017, 49, 2677.

[35] L. R. Gomes, J. N. Low, F. Cagide, A. Gaspar, J Reis, F. Borges, Acta Crystallogr. 2013, B69, 294. 
[36] T. C. Baddeley, L. R. Gomes, J. N. Low, J. M. S. Skakle, A. B. Turner, J. L. Wardell, G. J. R. Watson, Z. Kristallogr. 2017, 232, 317.

[37] W. T. Vellasco Junior, C. R. B. Gomes, T. R. A. Vasconcelos, J. L. Wardell, A. Otero-de-la-Roza, M. M. Jotani, E. R. T. Tiekink, Z. Kristallogr. 2016, 231, 663.

[38] L. N. F. Cardoso, T. C. M. Noguiera, C. R. Kaiser, J. L. Wardell, S. M. S. V. Wardell, M. V. N. de Souza, Z. Kristallogr. 2016, 231, 167.

[39] L. R. Gomes, J. N. Low, A. Fonseca, M. J. Matos, F. Borges, Acta Crystallogr. 2016, E72, 926.

[40] L. R. Gomes, J. N. Low, A. Fonseca, M. J. Matos, F. Borges, Acta Crystallogr. 2016, E72, 1121.

[41] L.-M. Song, J.-H. Gao, Jiegou Huaxue 2014, 33, 57.

[42] CrysAlis PRO 1.171.39.9g: Rigaku Oxford Diffraction, 2015.

[43] G. M. Sheldrick, Acta Crystallogr. 2015, A71, 3.

[44] C. B. Hübschle, G. M. Sheldrick, B. Dittrich, J. Appl. Crystallogr. 2011, 44, 1281.

[45] G. M. Sheldrick, Crystal structure refinement with SHELXL7. Acta Crystallogr. 2015, C71, 3.

[46] Mercury, CCDC 2017.

[47] A. L. Spek, Acta Crystallogr. 2009, D65, 148.

[48] A. L. Rohl, M. Moret, W. Kaminsky, K. Claborn, J. J. McKinnon, B. Kahr, Cryst. Growth Des. 2008, 8, 4517.

[49] S. K. Wolff, D. I. Grimwood, J. J. McKinnon, M. J. Turner, D. Jayatilaka, M. A. Spackman, Crystal Explorer, The University of Western Australia, 2012.

[50] Y. Zhao, D. G. Truhlar, Theor. Chem. Acc. 2008, 120, 215.

[51] S. Miertus, E. Scrocco, J. Tomasi, Chem. Phys. 1981, 55, 117.

[52] T. H. Dunning Jr, J. Chem. Phys. 1989, 90, 1007.

[53] R. A. Kendall, T. H. Dunning Jr, R. J. Harrison, J Chem. Phys. 1992, 96, 6796.

[54] M. J. Frisch, G. W. Trucks, H. B. Schlegel, G. E. Scuseria, M. A. Robb, J. R. Cheeseman, G. Scalmani, V. Barone, B. Mennucci, G. A. Petersson, H. Nakatsuji, M. Caricato, X. Li, H. P. Hratchian, A. F. Izmaylov, J. Bloino, G. Zheng, J. L. Sonnenberg, M. Hada,
M. Ehara, K. Toyota, R. Fukuda, J. Hasegawa, M. Ishida, T. Nakajima, Y. Honda, O. Kitao, H. Nakai, T. Vreven, J. A. Montgomery Jr., J. E. Peralta, F. Ogliaro, M. Bearpark, J. J. Heyd, E. Brothers, K. N. Kudin, V. N. Staroverov, R. Kobayashi, J. Normand, K. Raghavachari, A. Rendell, J. C. Burant, S. S. Iyengar, J. Tomasi, M. Cossi, N. Rega, J. M. Millam, M. Klene, J. E. Knox, J. B. Cross, V. Bakken, C. Adamo, J. Jaramillo, R. Gomperts, R. E. Stratmann, O. Yazyev, A. J. Austin, R. Cammi, C. Pomelli, J. W. Ochterski, R. L. Martin, K. Morokuma, V. G. Zakrzewski, G. A. Voth, P. Salvador, J. J. Dannenberg, S. Dapprich, A. D. Daniels, Ö. Farkas, J. B. Foresman, J. V. Ortiz, J. Cioslowski, D. J. Fox, Gaussian 09. Gaussian, Inc., Wallingford, CT, 2009.

[55] J. Bernstein, R. E. Davis, L. Shimoni, N. L. Chang, Angew. Chem. Int. Ed. Engl. 1995, 14, 1555.

[56] C. R. Groom, I. J. Bruno, M. P. Lightfoot, S. C. Ward, Acta Crystallogr. 2016, B72, 171.

[57] K. V. Sashidhara, M. Kumar, V. Khedgikar, P. Kushwaha, R. K. Modukuri, A. Kumar, J. Gautam, D. Singh, B. Sridhar, R. Trivedi, J. Med. Chem. 2013, 56, 109.

[58] H. Takahashi, H. Takechi, K. Kubo, T. Matsumoto, Acta Crystallogr. 2006, E62, 02553.

[59] V. B. Nagaveni, S. Naveen, T. O. Shrungesh Kumar, M. N. Kumara, K. M. Mahadevan, N. K. Lokanath, Der Pharma Chemica. 2016, 8, 392.

[60] Y.-F. Sun, S.-Y. Ma, D. Zhang, X.-L. Cheng, Yi.-X Kexue, Yu Guang Huaxue 2008, 26, 393.

[61] C.-L. Xu, S.-Y. Liu, C.-X. Wang, M.-Q. Zhao, Acta Crystallogr. 2009, E65, 02817.

[62] H. Moon, Q. P. Xuan, D. Kim, Y. Kim, J. W. Park, Cryst. Growth Des. 2014, 14, 6613.

[63] L.-C. Lo, J.-Y. Chen, C.-T. Yang, D.-S. Gu, Chirality 2001, 13, 266.

Supplementary Material: The online version of this article offers supplementary material (https://doi.org/10.1515/zkri-2018-2117). 


\title{
Graphical Synopsis
}

Ligia R. Gomes, John N. Low, Tanja van Mourik, Ligia S. da Silveira Pinto, Marcus V.N. de Souza and Jámes L. Wardell Crystal structures, Hirsfeld surface analysis and a computational study of four ethyl 2-oxo- $2 \mathrm{H}$-chromene-3-carboxylate derivatives: a survey of organyl 2-oxo2H-chromene-3-carboxylate structures

https://doi.org/10.1515/zkri-2018-2117

Z. Kristallogr. 2019; x(x): xxx-xxx
Synopsis: A study of the crystal structures and conformations of organyl ethyl 2-oxo- $2 \mathrm{H}$ chromene-3-carboxylates.
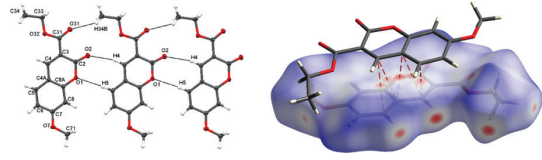

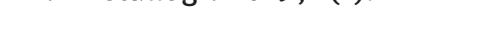

